\title{
Cold trap dehydration in the Tropical Tropopause Layer characterised by SOWER chilled-mirror hygrometer network data in the Tropical Pacific
}

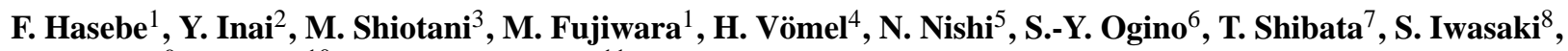 \\ N. Komala ${ }^{9}$, T. Peter ${ }^{10}$, and S. J. Oltmans ${ }^{11}$ \\ ${ }^{1}$ Faculty of Environmental Earth Science, Hokkaido University, Sapporo, Japan \\ ${ }^{2}$ Graduate School of Science, Tohoku University, Sendai, Japan \\ ${ }^{3}$ Research Institute for Suitainable Humanoshpere, Kyoto University, Uji, Japan \\ ${ }^{4}$ GRUAN Lead Center, Meteorologisches Observatorium Lindenberg, Lindenberg, Germany \\ ${ }^{5}$ Geophysical Institute, Kyoto University, Kyoto, Japan \\ ${ }^{6}$ Japan Agency for Marine-Earth Science and Technology, Yokosuka, Japan \\ ${ }^{7}$ Graduate School of Environmental Studies, Nagoya University, Nagoya, Japan \\ ${ }^{8}$ National Defense Academy, Yokosuka, Japan \\ ${ }^{9}$ Lembaga Penerbangan dan Antariksa Nasional, Bandung, Indonesia \\ ${ }^{10}$ Eidgenössische Technische Hochschule Zürich, Zurich, Switzerland \\ ${ }^{11}$ CIRES, University of Colorado and Earth System Research Laboratory, NOAA, Boulder, CO, USA
}

Correspondence to: F. Hasebe (f-hasebe@ees.hokudai.ac.jp)

Received: 7 September 2012 - Published in Atmos. Chem. Phys. Discuss.: 28 September 2012

Revised: 26 February 2013 - Accepted: 28 March 2013 - Published: 26 April 2013

\begin{abstract}
A network of balloon-borne radiosonde observations employing chilled-mirror hygrometers for water and electrochemical concentration cells for ozone has been operated since the late 1990s in the Tropical Pacific to capture the evolution of dehydration of air parcels advected quasihorizontally in the Tropical Tropopause Layer (TTL). The analysis of this dataset is made on isentropes taking advantage of the conservative properties of tracers moving adiabatically. The existence of ice particles is diagnosed by lidars simultaneously operated with sonde flights. Characteristics of the TTL dehydration are presented on the basis of individual soundings and statistical features. Supersaturations close to $80 \%$ in relative humidity with respect to ice $\left(\mathrm{RH}_{\mathrm{ice}}\right)$ have been observed in subvisible cirrus clouds located near the cold point tropopause at extremely low temperatures around $180 \mathrm{~K}$. Although further observational evidence is needed to confirm the credibility of such high values of $\mathrm{RH}_{\text {ice }}$, the evolution of TTL dehydration is evident from the data in isentropic scatter plots between the sonde-observed mixing ratio $(\mathrm{OMR})$ and the minimum saturation mixing ratio $\left(\mathrm{SMR}_{\min }\right)$
\end{abstract}

along the back trajectories associated with the observed air mass. Supersaturation exceeding the critical value of homogeneous ice nucleation $\left(\mathrm{OMR}>1.6 \times \mathrm{SMR}_{\min }\right)$ is frequently observed on the 360 and $365 \mathrm{~K}$ surfaces indicating that cold trap dehydration is in progress in the TTL. The near correspondence between the two $\left(\mathrm{OMR} \sim \mathrm{SMR}_{\min }\right)$ at $380 \mathrm{~K}$ on the other hand implies that this surface is not sufficiently cold for the advected air parcels to be dehydrated. Above $380 \mathrm{~K}$, cold trap dehydration would scarcely function while some moistening occurs before the air parcels reach the lowermost stratosphere at around $400 \mathrm{~K}$ where OMR is generally smaller than $\mathrm{SMR}_{\min }$.

\section{Introduction}

Understanding of stratospheric dryness begins with the idea that it must reflect the temperature history the air experienced before entering the stratosphere (Brewer, 1949; Newell and Gould-Stewart, 1981; Danielsen, 1982). Among 
many hypotheses, the "cold trap" theory in which air parcels are dehydrated during quasi-horizontal advection in the tropical tropopause layer (TTL) of the Western Tropical Pacific (Holton and Gettelman, 2001) is becoming widely accepted as one of the key dehydration processes. Thin cirrus clouds, too thin to be visually detected (often called subvisible cirrus clouds (SVCs); Jensen et al., 1996), are frequently observed even far from tropical convective systems (Winker and Trepte, 1998) suggesting that they are related to "cold trap" dehydration.

Aircraft observations such as those conducted during the Pre-AVE campaign have observed water vapour profiles with high vertical resolution (Richard et al., 2006) over tropical Central America. The Lagrangian temperature history along trajectories for the observed air parcels has been used to study the efficiency of dehydration (e.g. Jensen and Pfister, 2004; Fueglistaler et al., 2004, 2005; Fueglistaler and Haynes, 2005). Such an approach proved to be quite successful as compared to the Eulerian description in reproducing the water vapour field from meteorological data (e.g. Liu et al., 2010; Schoeberl and Dessler, 2011). The effectiveness of trajectory-based estimation of the dehydration efficiency, however, still awaits support from observational data. What is missing in such studies is in situ water vapour data in the TTL over the Western Tropical Pacific where "cold trap" dehydration is thought to be taking place.

The Soundings of Ozone and Water in the Equatorial Region (SOWER) project (Hasebe et al., 2000) is intended to accumulate ozone and water vapour profiles in the troposphere and the lower stratosphere (LS) in the Tropical Pacific by radiosonde observations (Vömel et al., 2002). It has been using chilled-mirror hygrometers such as the NOAA frostpoint hygrometer (FPH; Vömel et al., 1995), Snow White (SW; Fujiwara et al., 2003; Vömel et al., 2003) and the University of Colorado Cryogenic Frostpoint Hygrometer (CFH; Vömel et al., 2007a) to accurately measure water vapour profiles since 1998. These data constitute the basis for describing seasonal to decadal variations of TTL/LS water vapour in the tropics (Fujiwara et al., 2010).

The efficiency of "cold trap" dehydration in the TTL has been studied by comparing the observed water vapour mixing ratio (OMR) and the minimum saturation mixing ratio $\left(\mathrm{SMR}_{\min }\right)$ that air parcels have been exposed to during horizontal advection. $\mathrm{SMR}_{\min }$ has been estimated by using a bundle of isentropic backward trajectories corresponding to the air parcels observed by water vapour sondes (Hasebe et al., 2007). The OMR in the lower TTL proved to be about twice as much as $\mathrm{SMR}_{\min }$ in the Western Tropical Pacific. The information on ice particles given by simultaneously operated lidars indicates that SVCs do exist under supersaturation up to several ten percent (Shibata et al., 2007). However, the observational data are still limited and an accumulation of observational evidence is definitely needed to improve our understanding of the TTL dehydration.
In the present analysis, TTL water mixing ratio is examined on isentropes using the water vapour sonde data taken at Tarawa $\left(1.4^{\circ} \mathrm{N}, 172.9^{\circ} \mathrm{E}\right)$, Biak $\left(1.2^{\circ} \mathrm{S}, 136.1^{\circ} \mathrm{E}\right)$, Watukosek (7.6 $\left.\mathrm{S}, 112.7^{\circ} \mathrm{E}\right)$, Bandung $\left(6.9^{\circ} \mathrm{S}, 107.6^{\circ} \mathrm{E}\right)$, Kototabang $\left(0.2^{\circ} \mathrm{S}, 100.3^{\circ} \mathrm{E}\right)$, Hanoi $\left(21.0^{\circ} \mathrm{N}, 105.8^{\circ} \mathrm{E}\right)$, and San Cristóbal $\left(0.9^{\circ} \mathrm{S}, 89.6^{\circ} \mathrm{W}\right)$ since 1998 to shed light on the climatological differences along the equator. The longitudinal structure thus obtained must have been brought about by meteorological conditions such as local convective activity, isentropic level changes, season and El Niño/Southern Oscillation (ENSO) phase. Our primary focus is to examine whether the difference could be interpreted by the "cold-trap" hypothesis. We will thus pay special attention to the origin and Lagrangian temperature history of the observed air parcels, and derive mutual relationships between OMR and $\mathrm{SMR}_{\text {min }}$. The difference between the statistical features on each isentrope will be interpreted as an indication of the progress of dehydration (or hydration) as the air gradually ascends diabatically in the TTL. Before starting such analyses, efforts are made to create the most suitable dataset for this purpose by carefully estimating the observational errors and paying attention to the possible phase delay in the instrumental output. The data obtained by SW are not used, while those using the FPH and CFH are analysed to achieve better homogeneity in the analysed data. Homogeneous nucleation and supersaturation are discussed by combining the information on water concentration from sondes and ice particles from lidar and backscatter sondes when available. The estimation of the typical time scale for dehydration and the degree of supersaturation critical for initiating ice nucleation, both important measures of the efficiency of cold trap dehydration, will be done in a separate paper (Inai et al., 2013) that deals with the water vapour "match". The role of large scale atmospheric waves on the TTL dehydration will be discussed in a separate paper under preparation.

Section 2 introduces the SOWER campaigns including the sounding statistics and climatological conditions. The method of analysis for water vapour sonde data and corresponding trajectories is presented in Sect. 3. The results of both the statistical relationships between OMR and $\mathrm{SMR}_{\text {min }}$ and detailed meteorological interpretation for a couple of cases are described in Sect. 4. Discussion of the results is in Sect. 5 before summarising the findings in Sect. 6 .

\section{SOWER campaigns}

SOWER water vapour observations have been conducted on a campaign basis. Those stations that have operated frostpoint hygrometers FPH and CFH are listed in Table 1. The setting of the campaigns has shifted from the Eastern to the Western Tropical Pacific and the time of operation has been confined exclusively to boreal winter as our studies have become focused on the dehydration processes in the TTL. The early SOWER campaigns coincide with the developing of 
Table 1. Summary of water vapour sonde observations during each campaign. Only those with NOAA Frostpoint Hygrometer (FPH) and Cryogenic Frostpoint Hygrometer (CFH) are shown. See Fig. 1 for geographical location.

\begin{tabular}{rccccccc}
\hline & Hanoi & Kototabang & Bandung & Watukosek & Biak & Tarawa & San Cristóbal \\
\hline Lat. & 21.0 & -0.2 & -6.9 & -7.6 & -1.2 & 1.4 & -0.9 \\
Lon. & 105.8 & 100.3 & 107.6 & 112.7 & 136.1 & 172.9 & -89.6 \\
\hline 1998 & - & - & - & - & - & - & 3 (Mar/Apr), 3 (Sep) \\
1999 & - & - & - & - & - & - & 3 (Mar), 3 (Sep/Oct) \\
2000 & - & - & - & - & - & - & 6 (Nov/Dec) \\
2001 & - & - & - & 5 (Nov/Dec) & - & - & - \\
2002 & - & - & - & - & - & - & 2 (Aug) \\
2003 & - & - & $4($ Dec) & $3($ Jan $)$ & - & - & 1 (Mar) \\
2004 & - & - & $4($ Dec) & - & - & - & 2 (Jul) \\
2005 & - & - & - & - & - & $2($ Dec) & - \\
2006 & - & - & - & - & $9($ Jan $)$ & - & - \\
2007 & 6 (Jan) & 5 (Jan) & - & - & $6($ Jan) & 5 (Jan) & - \\
2008 & 5 (Jan) & 4 (Jan) & - & - & 7 (Jan) & - & - \\
2009 & 4 (Jan) & - & - & - & 4 (Jan) & - & - \\
\hline
\end{tabular}

the CFH and it was not until 2005 that consistently stable data became available from CFH. The following analysis begins with the development of an objective analysis scheme of sonde data that is not always uniform in the quality of observed values (Sect. 3).

SOWER aerosol observations have been made by Mie lidars installed at Bandung, Biak and Kototabang in Indonesia (Shibata et al., 2007), at Tarawa in Kiribati and on the research vessel "Mirai" (Fujiwara et al., 2009). The data shown in the present analysis are the backscattering coefficient at the $532 \mathrm{~nm}$ wavelength taken at Biak. See Shibata et al. (2012) for a more complete description of the Biak lidar system. Scattering from aerosols has also been observed, two launches thus far in SOWER campaigns, using the COBALD balloon-borne aerosol sonde (http://www.iac.ethz.ch/groups/ peter/research/Balloon_soundings/COBALD_sensor) developed by Frank G. Wienhold in the group of Thomas Peter at the Swiss Federal Institute of Technology (ETH). The optical properties of aerosol and cloud particles are measured by the backscatter ratio at wavelengths $455 \mathrm{~nm}$ and $870 \mathrm{~nm}$, by normalising the raw signal to the molecular scattering derived from the ambient molecular number density, using the temperature and pressure measured by the radiosonde (Brabec et al., 2012).

Before looking into details of the dehydration processes, it is useful to take a brief look at the averaged meteorological fields for representative campaigns. The latitude-longitude distributions of the horizontal wind components (arrows) and temperature (colour) on the $370 \mathrm{~K}$ isentropic surface are derived from the European Centre for Medium-Range Weather Forecasts (ECMWF) operational analyses and are shown as an average over the campaign period in Fig. 1. This isentrope has been chosen to be close to the cold point tropopause (CPT). The white circles are the location of the stations. There is obviously a clear interannual variations reflecting the ENSO condition and the phase of the quasi-biennial oscillation (QBO). The occurrence of ENSO generally shifts the western tropical cold core in the TTL to the east together with a general warming of the troposphere. The QBO modulates the zonal mean temperature as expected from the thermal wind relationship with the zonal wind (Plumb and Bell, 1982) leading to a warm (cold) TTL corresponding to the arrival of the descending westerly (easterly) phase at the lowermost stratosphere (Hasebe, 1994).

\section{Method of analysis}

\subsection{Processing of sonde data}

While the atmospheric pressure $p$ is usually used as an independent variable for radiosonde observations of temperature $T$ and horizontal wind components, it is also subject to observational uncertainties. To minimise possible mean bias in the raw pressure data, we have employed a pressure correction, usually small, using the method proposed by Inai et al. (2009) whenever simultaneous GPS height data are available.

The mixing ratio is used for the quantitative description of tracers as it is conserved following the atmospheric motion as long as chemical production/loss and physical condensation/evaporation are negligible. The primary quantity for the water vapour measurements by chilled-mirror hygrometers (such as FPH) is the frostpoint temperature $T_{\mathrm{fr}}$. It is converted to water mixing ratio $\chi$ referenced to the ambient pressure. In the present analysis, all observed values are projected on isentropic surfaces to take advantage of the conservation of both $\chi$ and potential temperature $\theta$ following adiabatic atmospheric motion. The data processing procedure that includes an objective evaluation of $\chi$ and its observational uncertainties on isentropes is described in the following. 

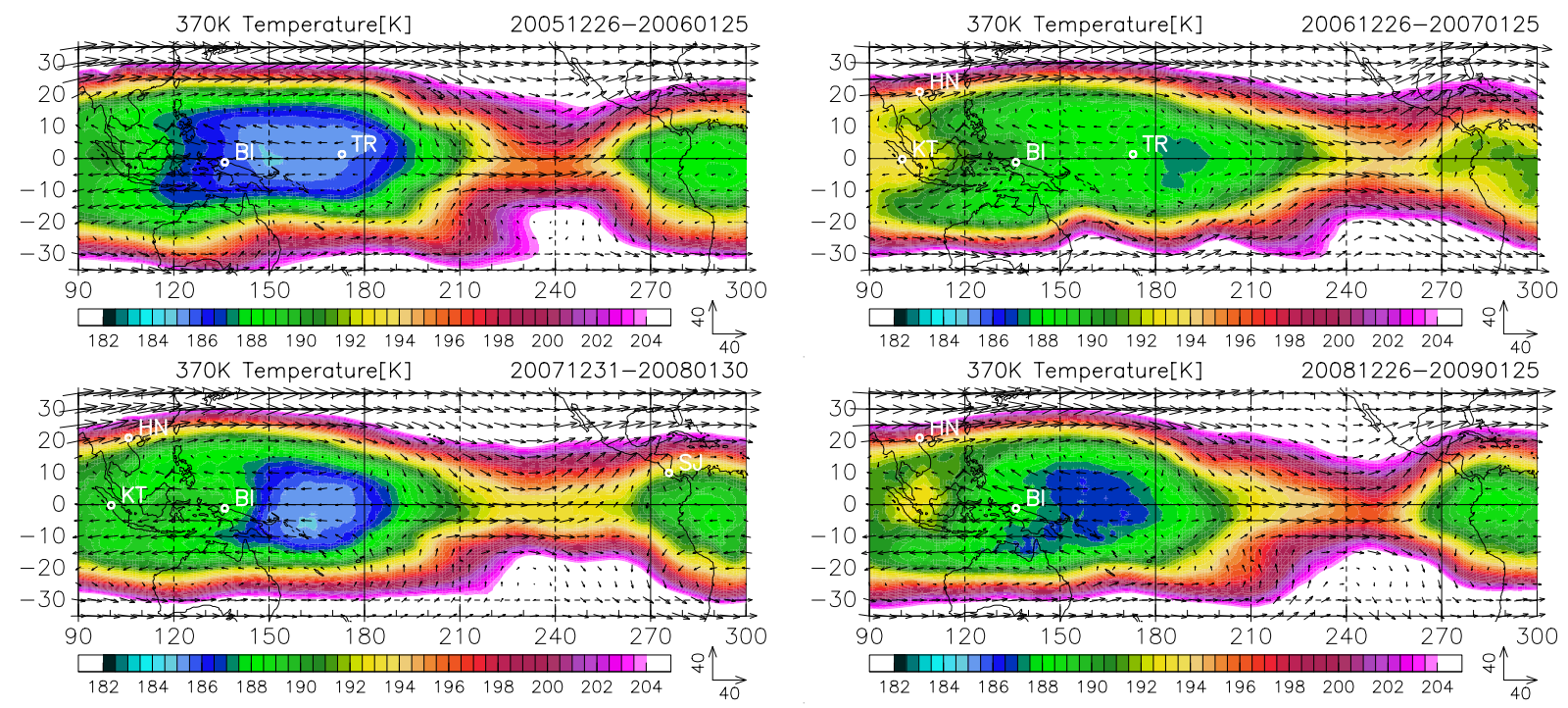

Fig. 1. Latitude-longitude sections of the mean horizontal wind component (vectors; scales of $40 \mathrm{~m} \mathrm{~s}^{-1}$ at the bottom right) and temperature (colour) on $370 \mathrm{~K}$ isentropic surface during four SOWER campaigns deduced from ECMWF operational analyses. The averages are taken for 31 days covering the primary campaign period. Ground stations operated during the corresponding period, Tarawa (TR), Biak (BI), Kototabang (KT) and Hanoi (HN), are indicated.

The frostpoint hygrometers maintain constant frost on a mirror by using its reflectance as a feedback signal to control the mirror temperature so that it is equal to the frostpoint temperature of the ambient air. The accuracy of the measurements depends on several aspects such as the temperature uniformity of the mirror and calibration of the thermistor. The largest source of the uncertainty for $\mathrm{CFH}$ measurements is, however, the stability of the feedback controller resulting in the overall uncertainty of $0.51{ }^{\circ} \mathrm{C}$ in $T_{\text {fr }}$ corresponding to a range from $4 \%$ in the tropical lower troposphere to $10 \%$ in the middle stratosphere in water mixing ratio (Vömel et al., 2007a). What is specific for the frostpoint hygrometer measurements is the finite length of time for the frost on the mirror to achieve equilibrium with the environment. In the lower tropospheric condition, e.g., $20^{\circ} \mathrm{C}$, the response time $\tau$ for the instrument to maintain frost on the mirror is short enough to be neglected. However, it becomes longer higher up in the atmosphere due to lengthening of the time for vapour-water and vapour-ice equilibrium on the mirror to be achieved. It may reach $10 \mathrm{~s}$ and as long as $80 \mathrm{~s}$ under the condition of $-30^{\circ} \mathrm{C}$ and $-60^{\circ} \mathrm{C}$, respectively, in the case of SW (Fujiwara et al., 2003). This is one of the reasons we do not use $\mathrm{SW}$ in this study. The CFH, on the other hand, is designed to optimize the individual settings of the on board feedback controller so that $\tau$ be minimum without causing spurious fluctuations in the observed data (Vömel et al., 2007a,b). However, in the upper troposphere and lower stratosphere, as is discussed later, $\tau$ could be much longer than the sampling interval of about $7 \mathrm{~s}$ for TMAX-C and $1.4 \mathrm{~s}$ for V2C systems that transmit telemetry data to the ground station. As a result, fluctuations shorter than $\tau$ in the raw radiosonde data are mostly an artifact created by the instrumental feedback system. This is clearly seen in the early NOAA/FPH data that rely on the TMAX-C system (Fig. 2). The diagram at the topleft illustrates the ascending (green) and descending (purple) vertical profiles of water mixing ratio taken at San Cristóbal in March 1998. Some detailed structures, if any, are not resolved by relatively large uncertainties in the fluctuations in the data. Such instrumental noise is greatly reduced in the most recent ten years due to the improvement in the mirror temperature control system as can been seen in the top-right of the figure showing the similar profile observed at Biak in January 2008 with the CFH using the V2C system.

Such instrumental noise can be reduced by smoothing the sequence of raw frostpoint temperature profiles as long as the noise can be regarded as random. The details of data processing on pressure levels including the smoothing procedure are described in Appendix A1. The smoothing with the time interval similar to that for $T_{\text {fr }}$ has been applied to $p$ and $T$, both primary observed quantities for radiosondes, to guarantee mutual consistency among derived quantities. It should be mentioned, however, that the response time for $p$ and $T$ is much shorter than the sampling intervals in all observation range. The estimated uncertainties in $p$ and $T$ are mostly composed of natural variability rather than instrumental noise. The details of the estimation of uncertainties in the smoothed values are also given in Appendix A1.

We now have the smoothed values of pressure $\bar{p}_{i}$, temperature $\bar{T}\left(\bar{p}_{i}\right)$, and frostpoint temperature $\bar{T}_{\mathrm{fr}}\left(\bar{p}_{i}\right)$, together with the estimates of errors $\Delta p\left(\bar{p}_{i}\right), \Delta T\left(\bar{p}_{i}\right)$, and $\Delta T_{\mathrm{fr}}\left(\bar{p}_{i}\right)$, respectively, for each sounding level $i$. The partial pressure of water is given by the saturation water pressure 

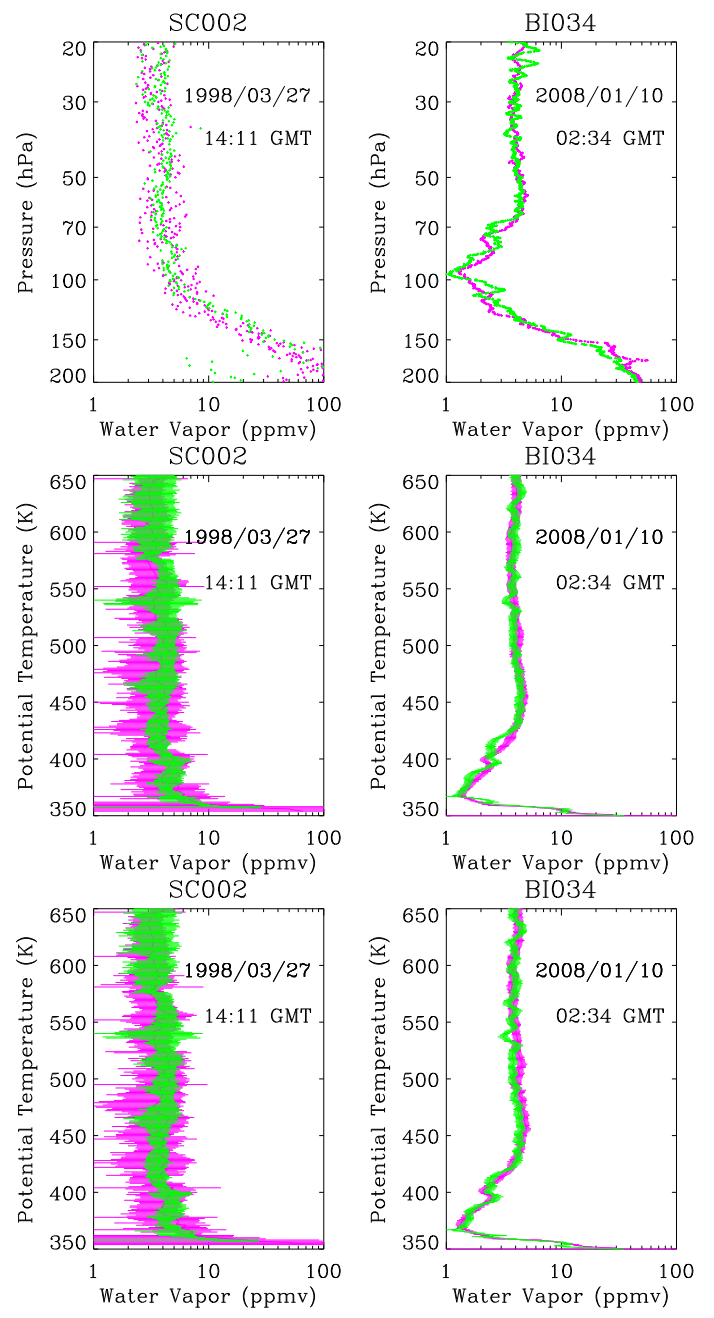

Fig. 2. Examples of water mixing ratio (ppmv) profiles taken at (left) San Cristóbal (SC) in March 1998 and (right) Biak (BI) in January 2008. Ascending (green) and descending (purple) profiles are superposed to visualise the phase delay associated with the upward and downward sonde motion. (Top) raw data, (middle) same data projected on isentropic coordinates, and (bottom) same with phase correction applied. See Appendix for the data processing procedure and the derivation of uncertainties shown in horizontal bars.

$e_{\text {sat }}$ corresponding to $\bar{T}_{\mathrm{fr}}$. The Goff-Gratch equation (Goff and Gratch, 1946; Murray, 1967; Murphy and Koop, 2005; Hasebe et al., 2007) is used for its estimation. The water mixing ratio $\chi\left(\bar{p}_{i}\right)$ is readily derived by dividing $e_{\text {sat }}$ by $\bar{p}_{i}$. Before projecting $\chi\left(\bar{p}_{i}\right)$ on isentropes, we estimate the errors in $\theta\left(\bar{p}_{i}\right)$ as well as $\chi\left(\bar{p}_{i}\right)$. The detailed procedure is given in Appendix A1. All these quantities are taken into account in deriving the uncertainties of water mixing ratio on isentropes. The procedure for the projection of the pressure-based values on isentropes is described in Appendix A2. The results are shown in the middle of Fig. 2. The horizontal bars indicate the range of uncertainties that arise from total (both instrumental and natural) variability. Due to the mutual de- pendency of errors among the data used in the smoothing, it is not appropriate to identify any specific value for the probability that the population mean sits within the range of these bars (see Appendix A1). However, it does provide useful information on the range of uncertainties in the obtained profiles.

Some differences between the ascending (green) and descending (purple) profiles are noted in the range between 350 and $420 \mathrm{~K}$ from the Biak data (Fig. 2 middle right) exhibiting a wavy structure with maxima and minima located at a higher (lower) isentrope in the ascending (descending) data. This is mostly attributable to the delay in the response of the frost on the mirror of the hygrometer rather than the difference in the sampled air volume. Full understanding of such behaviour requires adequate knowledge of the mirror temperature control system. In the present analysis, we take a practical approach by applying inverse filtering to the observed data to compensate for the phase delay as much as possible. The method of phase correction is described in Appendix A3. The adopted values of the response time $\tau$ are $4 \mathrm{~s}$ in the upper troposphere $(250>p \geq 150 \mathrm{hPa}), 8 \mathrm{~s}$ in the lower TTL $(150>p \geq 120 \mathrm{hPa})$, and $10 \mathrm{~s}$ in the upper TTL and the stratosphere $(p<120 \mathrm{hPa})$ while the lag is neglected $(\tau=0)$ in the lower- and middle troposphere $(p \geq 250 \mathrm{hPa})$. The corrected profiles are shown at the bottom of Fig. 2. Unfortunately the sharp minimum in the ascending data near $370 \mathrm{~K}$ cannot be reproduced from the descending data as the instrument does not capture the signal during descent. However, we can see the phase correction working reasonably well to compensate for the phase lag arising from the limitations of the observational principle of the frostpoint hygrometer. This correction gives greater confidence in the degree of supersaturation derived from the analysis (Sect. 4).

\subsection{Trajectory analysis}

The water content of any air parcel observed by sondes is controlled by many factors, in addition to the amount of water it originally contained, such as the dehydration it has experienced during horizontal advection and hydration due to evaporation of cloud particles and/or precipitation from above. The degree of dehydration the observed air parcels are subjected to is examined by using the temperature history along the trajectories. For this purpose, isentropic backward trajectories are calculated using the global analysis field.

We employ the $1.125^{\circ}$ latitude by $1.125^{\circ}$ longitude horizontal resolution and 60 model-level (L60) version of the ECMWF reanalyses ERA40 in six-hour intervals until December 2002. After that the $1^{\circ}$ by $1^{\circ}$ six-hour interval ECMWF operational analysis L60 dataset is used until January 2006 and L91 thereafter. Because of the limited spatiotemporal resolution of the model, the trajectory calculations based on the global analysis field cannot eliminate errors arising from small scale features unresolved in the model. Although any complete assessment of the accuracy 

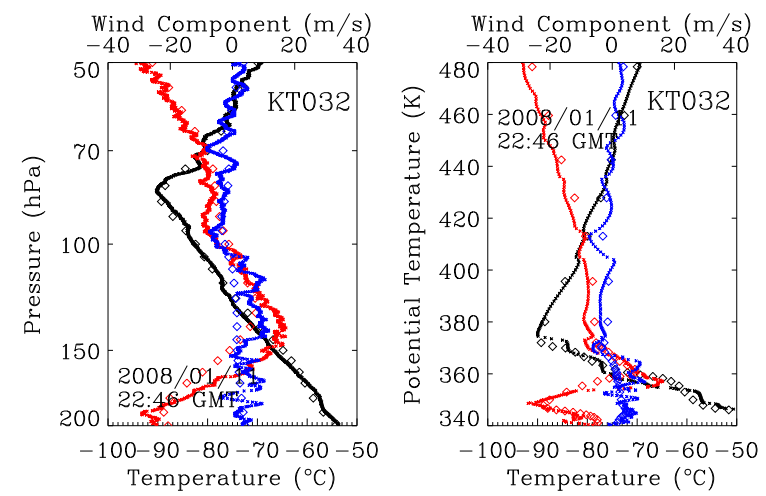

Fig. 3. Profiles of temperature (black) and zonal (red) and meridional (blue) wind components as a function of (left) pressure (hPa) and (right) potential temperature $(\mathrm{K})$ at Kototabang observed on 11 January 2008. Radiosonde observations (densely populated crosses) and corresponding ECMWF analysis interpolated to the station (diamonds) are compared.

of the derived trajectories is not feasible, some comparisons of our sonde data with the global analysis field will be helpful in getting an idea of the limitation of such calculations. Before calculating the trajectories, a brief survey is conducted by comparing the vertical profiles of temperature and wind components provided by the ECMWF analysis field against our sonde observations. Note that ECMWF does not include SOWER data in the analyses and thus the sets to be compared in the following are mutually independent.

Figure 3 shows an example from such comparisons. The sequences of crosses that look like heavy lines are the sonde profiles of temperature (black) and zonal (red) and meridional (blue) wind components, while sparsely plotted diamonds are those interpolated to the station at the time of launch from the six-hour interval ECMWF gridpoint data (left). ECMWF data on model levels are interpolated to prescribed pressure levels with an adequate interval so as not to lose the model's vertical resolution. The sonde data are projected on potential temperature surfaces in every $0.2 \mathrm{~K}$ between 340 and $360 \mathrm{~K}, 0.5 \mathrm{~K}$ between 360 and $380 \mathrm{~K}$, and every $1.0 \mathrm{~K}$ from 380 to $700 \mathrm{~K}$. The results are shown on the right where sonde data are illustrated in crosses while the ECMWF data converted from pressure coordinates are shown in diamonds. As is expected, small scale features in sonde data are missing in the interpolated ECMWF data even though the overall features agree reasonably well between the two datasets.

Statistical features derived from such comparisons between sonde and ECMWF fields are illustrated in Fig. 4, that shows the mean bias of the analysis field against sonde data at SOWER stations with superimposed bars corresponding to the confidence interval of $99 \%$. The top and bottom panels are drawn by using the data before and after December 2006, respectively, when the operational use of GPS temperature data by COSMIC started in ECMWF. There are some no- ticeable biases, one in zonal wind at around $380 \mathrm{~K}$ and $440 \mathrm{~K}$ in the former period (centre; red) and the other in temperature at around $430 \mathrm{~K}$ and $360 \mathrm{~K}$ (left; black) in the former and the latter period, respectively. It is interesting to note that the biases are reduced in the statistics after December 2006 (bottom) not only in temperature but also in wind components. The improvement in the quality of meteorological fields in general may indicate the model's response to the high resolution COSMIC temperature data adjusting the dynamical fields to be consistent with observed temperature. However, there is one exception; the cold bias in ECMWF temperature at around $360 \mathrm{~K}$, common in both periods, becomes statistically significant in the latter. This bias will be taken into account in the estimation of saturation mixing ratio along the trajectories.

Figure 5 shows another type of comparison that illustrates time series of temperature (black) and zonal (red) and meridional (blue) wind components on the $370 \mathrm{~K}$ isentrope at Biak covering the 2006 (top) and 2007 (bottom) campaigns in January. The overall agreement is good in the latter while some noticeable differences are found in the former. Although it is hard to draw generalised conclusion from our limited comparisons, it is quite impressive to see the improvement of the ECMWF analysis in the COSMIC era.

In spite of such shortcomings in the analysis field, trajectory calculations have proven to be a convenient tool for many purposes including the dehydration studies. To cope with the uncertainties and to try to deduce as much information as possible, we will take a probabilistic approach throughout our study. The advected air parcel is expressed by a set of segments initialised in the area representative of the air mass observed by sondes. This will help visualise the deformation of the air parcels due to wind shear and the bifurcation of the trajectories at the saddle point encountered along the advection (e.g., south of Tarawa in the bottom panel of Hasebe et al., 2007, Fig. 1). Figure 6 illustrates the distribution of such segments on initialisation (equally spaced crosses filling the circle over the station with the density of 10 segments per degree) superposed on three sonde flight tracks (solid lines in colour). The diameter of the circle has been chosen to be $1^{\circ}$ in latitude/longitude to cover almost the entire flight track of typical sonde flights with the intention of covering the range of uncertainties in the location of the observed air mass. The temperature history of each air mass observed by sondes is examined by using a bundle of 81 trajectories initialized at these points.

An example from such trajectories is shown in Fig. 7, which shows the horizontal projection of seven-day backward trajectories on the $353 \mathrm{~K}$ isentrope corresponding to the sonde flight from Biak on 8 January 2006. Those on the top panel are colour-coded by the saturation mixing ratio (SMR) for the advected air parcel estimated from the ECMWF temperature field using the Goff-Gratch equation. We can see that the air parcel was exposed to a relatively high SMR about 3-4 days prior to observation as indicated 

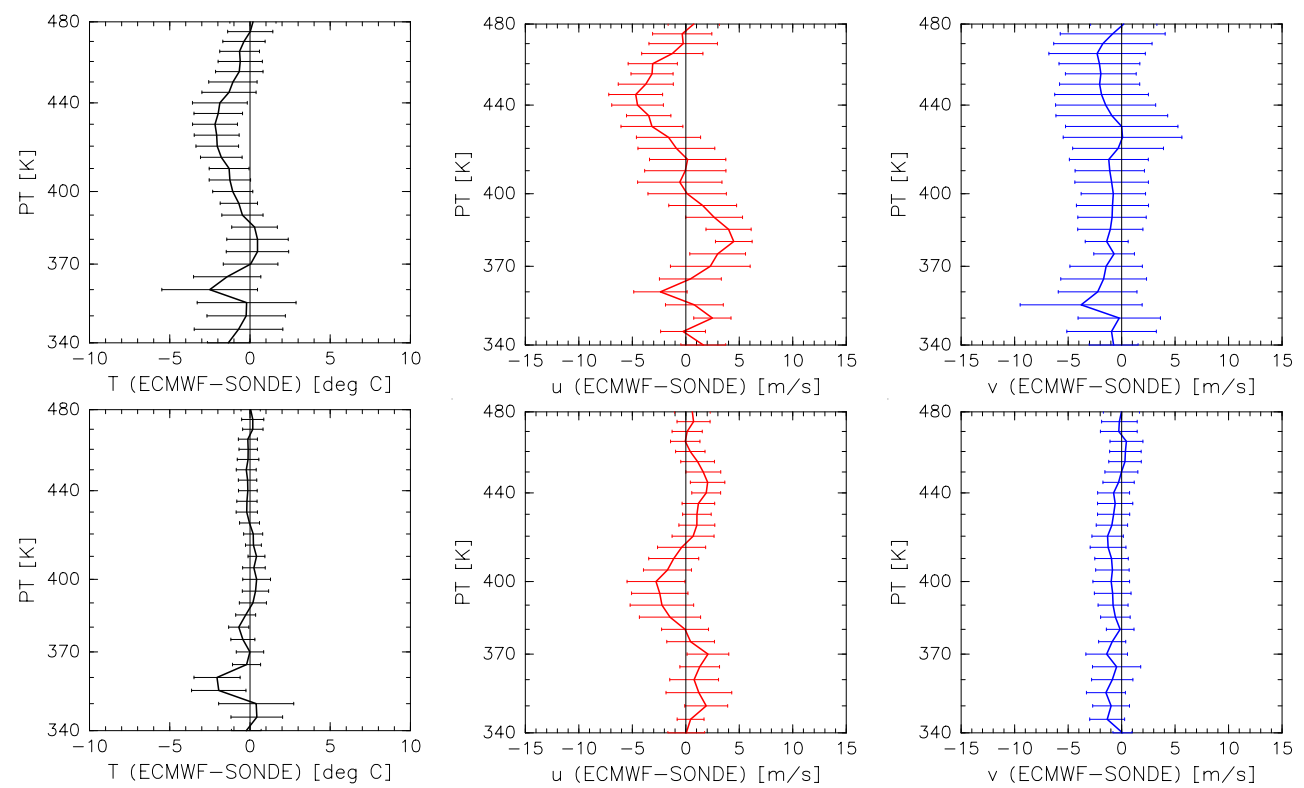

Fig. 4. Ensemble mean differences of (left) temperature and (centre) zonal and (right) meridional wind components between radiosonde observations and ECMWF analysis illustrated as a function of potential temperature. Estimations are made by using SOWER station data at Tarawa, Biak, Bandung and Kototabang for the period (top) before and (bottom) after December 2006. The horizontal bars correspond to the confidence interval of $99 \%$.

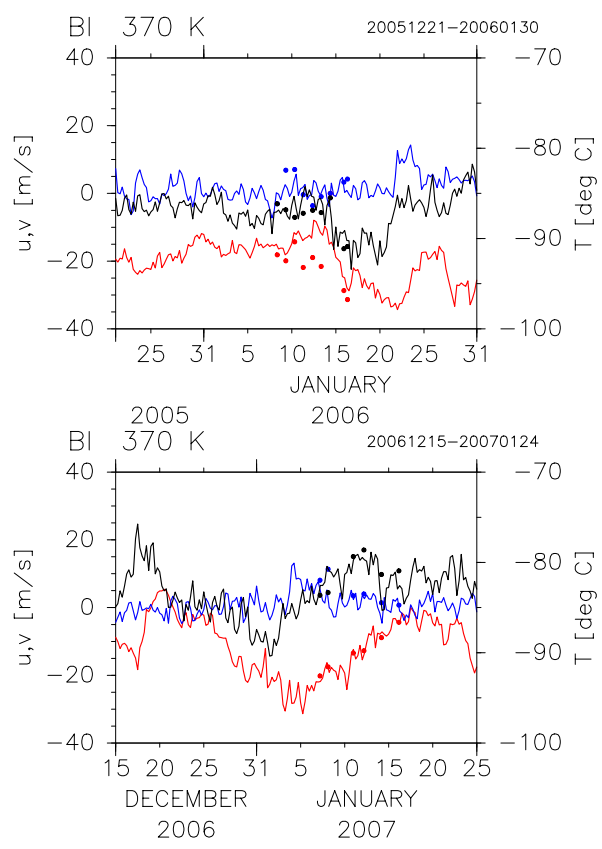

Fig. 5. Time series of temperature (black) and zonal (red) and meridional (blue) wind components based on $6 \mathrm{~h}$ interval ECMWF analysis interpolated to $370 \mathrm{~K}$ potential temperature level at Biak station for the period (top) from 21 December 2005 to 30 January 2006 and (bottom) from 15 December 2006 to 24 January 2007. Sonde observations are superposed by dots.

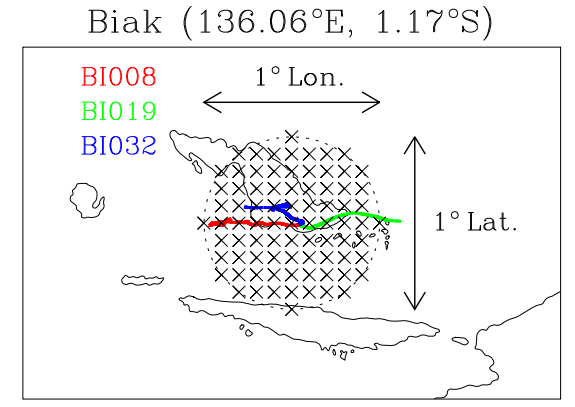

Fig. 6. Initial location of air segments set for calculating backward trajectories distributed with an interval of $0.1^{\circ}$ in a diameter of $1^{\circ}$ centred at Biak sonde station. Underlying solid curves are the horizontal projection of three sonde flight tracks drawn for the purpose of reference.

by the orange portion of the trajectories. It experienced low SMR at the early and final stages of the advection as judged by light green. The possible influence of penetrating deep convection on the advected air parcel is examined by comparing instantaneous air temperature $T$ given by the analysis field with the underlying earth's equivalent blackbody temperature $T_{\mathrm{bb}}$ observed by the geostationary meteorological satellites Geostationary Operational Environmental Satellite9 (GOES-9) and Multi-functional Transport Satellite-1 Replacement (MTSAT-1R). The resolution of $T_{\mathrm{bb}}$ is 20 pixels per degree (i.e., roughly $5 \times 5 \mathrm{~km}$ ) with a one hour time interval. The results are shown on the bottom panel of the figure and shows the trajectories colour coded by the difference 

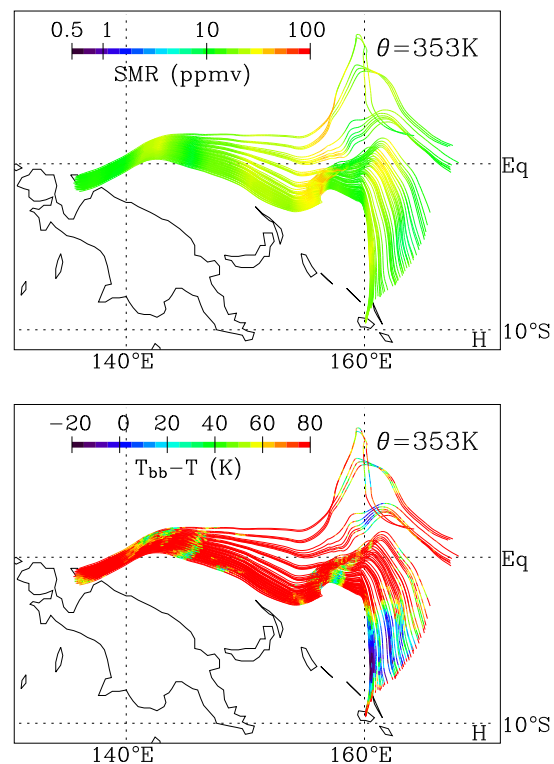

Fig. 7. Seven-day isentropic backward trajectories started from Biak (left end) on $353 \mathrm{~K}$ surface corresponding to the sounding on 8 January 2006. Trajectories are colour-coded by (top) saturation mixing ratio estimated from ECMWF temperature analysis and (bottom) the difference between the equivalent blackbody temperature (brightness temperature) $T_{\mathrm{bb}}$ observed by geostationary satellite and the temperature $T$ of the advected air parcel $\left(\delta T_{\mathrm{bb}} \equiv\right.$ $\left.T_{\mathrm{bb}}-T\right)$.

between $T_{\mathrm{bb}}$ and $T$. The dark colours such as purple indicate that the difference between the two $\left(\delta T_{\mathrm{bb}} \equiv T_{\mathrm{bb}}-T\right)$ is negative meaning that the cloud top is colder and thus higher than the advected air parcel. The southern portion of the trajectories indicates that the air parcel may have encountered deep convection and that the air mass may have been replaced by convectively lifted lower-tropospheric humid air during the early stage of advection. This information will be used in the interpretation of the water content of the air mass observed by hygrometers.

\section{Results}

\subsection{Case study from individual soundings}

In this subsection, two selected profiles are discussed in detail with the aim of providing a meteorological interpretation of the overall results in terms of TTL dehydration. The left-hand panel of Fig. 8 shows the vertical profiles of temperature $(T$; black $)$, frostpoint temperature $\left(T_{\mathrm{fr}}\right.$; green $)$, and ozone mixing ratio $\left(\mathrm{O}_{3}\right.$; purple) observed on 11 January 2008 at Biak. The lower boundary of TTL, implied by the upward ozone increase from its tropospheric value of about $25 \mathrm{ppbv}$, is found at around $360 \mathrm{~K}$. The atmosphere below $354 \mathrm{~K}$ potential temperature is near saturation as seen from the almost overlapping profiles of $T$ and $T_{\mathrm{fr}}$. Similarly, the air between
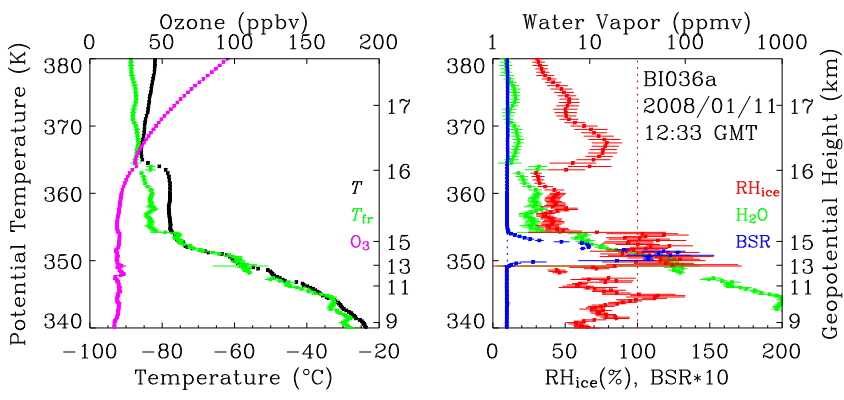

Fig. 8. Vertical profiles of (left) temperature (black; ${ }^{\circ} \mathrm{C}$ ), frostpoint temperature observed by $\mathrm{CFH}\left(T_{\mathrm{fr}}\right.$; green; $\left.{ }^{\circ} \mathrm{C}\right)$, and ozone mixing ratio (purple; ppbv in upper scale), and (right) water mixing ratio converted from $T_{\mathrm{fr}}$ shown on the left (green; ppmv in upper scale), relative humidity with respect to ice $\left(\mathrm{RH}_{\mathrm{ice}} ;\right.$ red; \%), and backscattering ratio (BSR) observed by COBALD (blue channel: $455 \mathrm{~nm}$ ) multiplied by 10 (blue) taken from the ascending portion of the sounding launched at 12:33 GMT on 11 January 2008 at Biak. Horizontal bars are the estimated uncertainties as described in Appendix A2. Dashed vertical lines on the right panel correspond to $100 \%$ in $\mathrm{RH}_{\text {ice }}$ (red) and 1 in BSR (blue).

$363 \mathrm{~K}$ and $368 \mathrm{~K}$ is close to saturation $\left(\mathrm{RH}_{\mathrm{ice}}>70 \%\right)$. The layer between $355 \mathrm{~K}$ and $363 \mathrm{~K}$, sandwiched between humid regions, is almost isothermal and exhibits little change in $T_{\mathrm{fr}}$ as well. The fact that $T_{\mathrm{fr}}$ is appreciably smaller than $T$ indicates the dryness of this layer, as can be seen from the right panel of Fig. 8, where the corresponding profiles of water mixing ratio (green) and relative humidity with respect to ice $\left(\mathrm{RH}_{\text {ice }}\right.$; red) show low values. The profiles of $\mathrm{RH}_{\text {ice }}$ stay within the range between $25 \%$ and $50 \%$ in this layer in contrast to the near saturation below and above. No ice particles were detected by the COBALD Backscatter Sonde in this dry layer as can be seen from the profile of the backscatter ratio (BSR; blue).

In the saturated layer below $354 \mathrm{~K}$, COBALD shows a pronounced cirrus layer, with a geometric thickness of about $2 \mathrm{~km}$ and an estimated optical thickness of about 0.1 . Although the uncertainties of $\mathrm{RH}_{\text {ice }}$ in this layer are relatively large, the maximum value within the particle layer reaches $129 \pm 14 \%$, i.e., clearly supersaturated. This cloud layer is also detected by the lidar at Biak station. Figure 9 shows the time-height section of the backscattering coefficient at $532 \mathrm{~nm}$ observed by lidar. We can see clouds at the altitude range from 12 to $16 \mathrm{~km}$ illustrated in warm colours. The large values of the depolarisation ratio (not shown) simultaneously observed with the backscattering coefficient indicate that the cloud particles are frozen ice (cirrus clouds).

It is interesting to investigate the meteorological basis for this layered structure from a Lagrangian point-of-view. We can see that the profile shown in Fig. 8 is directly related to the atmospheric flow pattern and the region from which the air masses originated. Figure 10 illustrates the horizontal projection of the isentropic backward trajectories colour-coded 


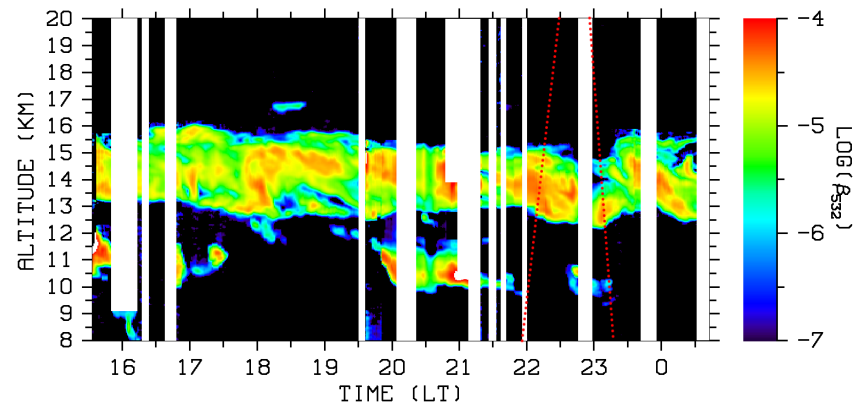

Fig. 9. Time-height section of the backscattering coefficient $\left(\mathrm{m}^{-1} \mathrm{str}^{-1}\right)$ at $532 \mathrm{~nm}$ observed by the Biak lidar. Red dotted lines: superposed ascending and descending sonde flight tracks. White bands: periods with low data quality. Local time at Biak shown in abscissa is GMT +9 . The range in which the COBALD BSR exceeds 10 in Fig. 8 corresponds to altitudes between 13.2 and $15.0 \mathrm{~km}$.

by the instantaneous saturation mixing ratio (SMR) on the $370 \mathrm{~K}$ (upper humid layer), $360 \mathrm{~K}$ (middle dry layer) and $353 \mathrm{~K}$ (in the midst of the saturated layer) surfaces for the sonde profile shown in Fig. 8. The SMR for these air masses regularly has relatively high values while they traveled in mid-latitudes, but it becomes low after they reached the region within \pm 10 degrees latitude of the equator, where they were exposed to low temperature. This is due to the general tendency of the isentropes in the TTL, e.g., $360 \mathrm{~K}$, to be higher in the tropics than in mid-latitudes. However, we can readily see the clear difference of the $360 \mathrm{~K}$ air masses against those on the $353 \mathrm{~K}$ and $370 \mathrm{~K}$ surfaces. Those at $360 \mathrm{~K}$ originated from the northern mid-latitudes while those at both $353 \mathrm{~K}$ and $370 \mathrm{~K}$ have been advected from the southern mid-latitudes. The gross features of the vertical structure could be thus related to the origin of the air masses on the hemispheric scale.

If we look in more detail at the SMR along trajectories, we can see that the air parcels have experienced a couple of cold events. For example, those at $370 \mathrm{~K}$ were advected from an extremely cold region far east of Papua New Guinea with the SMR as low as $0.5 \mathrm{ppmv}(182.4 \mathrm{~K}$ on $169.1 \mathrm{hPa})$, which is much lower than the observed mixing ratio (OMR) of $1.7 \pm 0.2 \mathrm{ppmv}$ over Biak. The difference between OMR and SMR is a measure of the dehydration efficiency observationally deduced. Similar calculation for the air parcel at $360 \mathrm{~K}$ shows that the minimum SMR during the seven days $\left(\mathrm{SMR}_{\mathrm{min}}\right)$ is about $1.4 \mathrm{ppmv}(185 \mathrm{~K}, 99 \mathrm{hPa})$ as compared to the OMR of $2.9 \pm 0.4 \mathrm{ppmv}$, and $\mathrm{SMR}_{\min }=5.4 \mathrm{ppmv}$ $(196 \mathrm{~K}, 160 \mathrm{hPa})$ against $\mathrm{OMR}=9.8 \pm 1.7 \mathrm{ppmv}$ at $353 \mathrm{~K}$. What is clear for those at $353 \mathrm{~K}$ is that the parcels over Biak are just experiencing the low temperature (197.6 K) comparable to that of $\mathrm{SMR}_{\min }$, consistent with the existence of ice particles confirmed by COBALD and lidar.

In order to examine the possible intrusion of deep convection into the advected air masses, Fig. 11 compares the

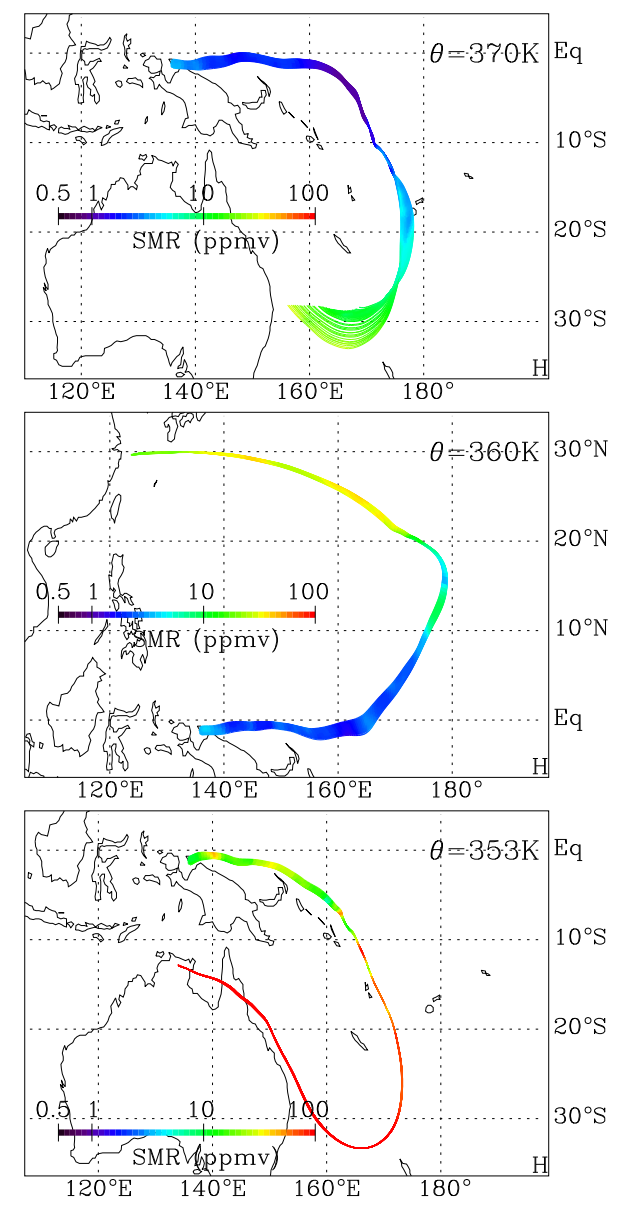

Fig. 10. Seven-day isentropic backward trajectories started from Biak on (top) 370, (middle) 360, and (bottom) $353 \mathrm{~K}$ surfaces corresponding to the observation shown in Fig. 8. Trajectories are colourcoded by saturation mixing ratio estimated from ECMWF analysis.

SMR along the trajectories with the underlying equivalent blackbody temperature $\left(T_{\mathrm{bb}}\right)$. The top panel is the same as the bottom of Fig. 10, but drawn only for the three days before sonde observation, while the bottom is the same as the top except that the trajectories are colour-coded by the difference of the instantaneous $T_{\mathrm{bb}}$ from the air temperature $T$ $\left(\delta T_{\mathrm{bb}} \equiv T_{\mathrm{bb}}-T\right)$. The air parcels experienced a relatively cold environment four times during the three days; just over Biak, about a half day, about $45 \mathrm{~h}$, and about $65 \mathrm{~h}$ before arrival at Biak. Between these events, they passed through a relatively warm environment, which means that they were advected at relatively high pressure (low altitudes). The last of these events is found when they passed $140^{\circ} \mathrm{E}$. Between this event and the arrival over Biak at 5 to 11 GMT on 11 January 2008, some portion of the air parcels may have encountered deep convection as values less than $20 \mathrm{~K}$ are observed for $\delta T_{\mathrm{bb}}$. It is hard to identify its critical value for which deep convection actually reaches air parcels drifting above, but the minimum value of $14 \mathrm{~K}$ detected in this case may be low 

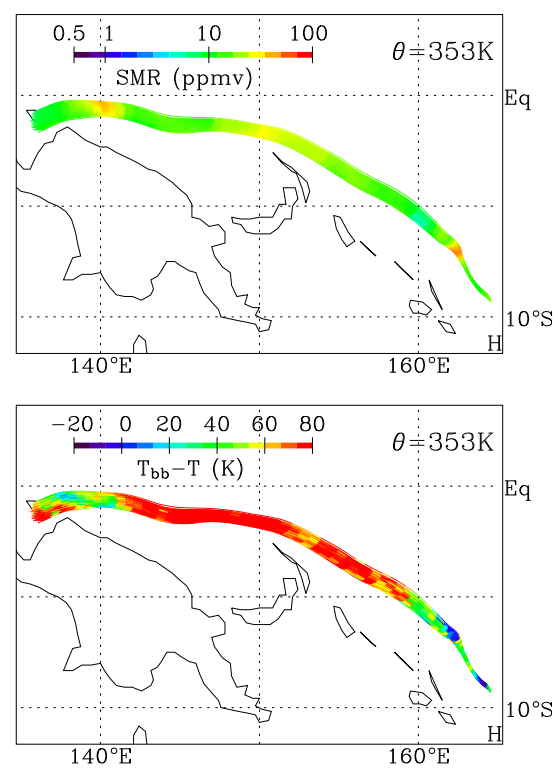

Fig. 11. (Top) the same as the bottom panel (353 K) of Fig. 10, but for three-day portion of the backward trajectories, and (bottom) the same but colour-coded by the difference between the equivalent blackbody temperature $T_{\mathrm{bb}}$ observed by geostationary satellite and the air temperature $T\left(\delta T_{\mathrm{bb}} \equiv T_{\mathrm{bb}}-T\right)$. Dark colours indicate penetrating convective clouds while warm colours cloud-free air at or above trajectory.

enough to suspect intrusion by deep convection. The saturation around $353 \mathrm{~K}$ over Biak (Fig. 8) is inferred from possible intrusion of deep convection within several hours before the sonde observations. There were no such events $\left(\delta T_{\mathrm{bb}} \leq 20 \mathrm{~K}\right)$ for the trajectory sets on $360 \mathrm{~K}$ and $370 \mathrm{~K}$.

Another sounding shown in Fig. 12 exhibits very humid layers in terms of relative humidity. One is the thin layer centred at $351 \mathrm{~K}$ and the other is the broad region (in isentropic coordinates) around the cold-point tropopause (CPT) near $380 \mathrm{~K}$. The former, sitting just below the TTL lower boundary with a marked ozone increase and a sudden drop of frostpoint temperature, is not discussed here as the behaviour of the instrument raises questions on the validity of the observed values. In the latter case around $380 \mathrm{~K}$, the layer of supersaturation spans $374.0 \mathrm{~K}(17551 \mathrm{~m})$ to $402.0 \mathrm{~K}(18720 \mathrm{~m})$ in potential temperature with the maximum $\mathrm{RH}_{\text {ice }}$ value reaching $179 \pm 14 \%$ on $378.5 \mathrm{~K}(18247 \mathrm{~m})$. The atmospheric temperature on this level is $180.2 \mathrm{~K}\left(-93.0^{\circ} \mathrm{C}\right)$, which is slightly higher than that of the CPT of $179.8 \mathrm{~K}\left(-93.3{ }^{\circ} \mathrm{C}\right)$ found in the raw sonde record at $379.5 \mathrm{~K}(18334 \mathrm{~m})$. This supersaturation is found within the cirrus clouds as can be seen from the lidar backscatter signal (Fig. 13). The $\mathrm{RH}_{\text {ice value }}$ of $179 \pm 14 \%$ within the cirrus is extremely high, although similar values have been reported previously (Krämer et al., 2009). As expected, the subsaturated layer at around $369.0 \mathrm{~K}$ $(16982 \mathrm{~m})$ with the $\mathrm{RH}_{\text {ice }}$ value of $96 \pm 10 \%$ shows no signal in the cross-section of the lidar backscattering coefficient.
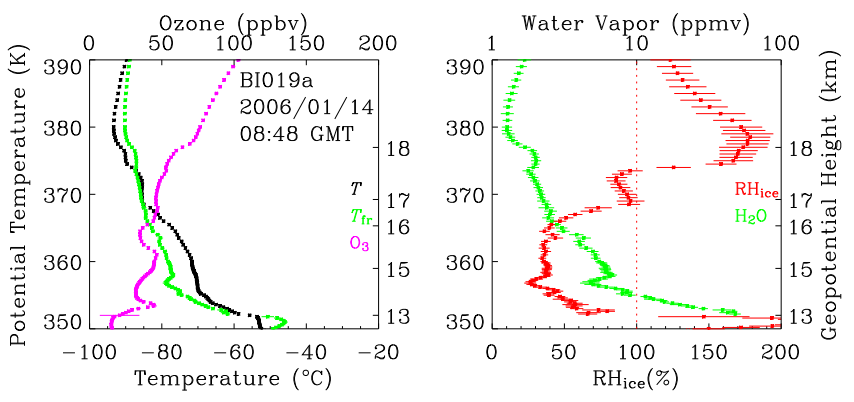

Fig. 12. The same as Fig. 8 but for the launch conducted at 08:48 GMT on 14 January 2006. Note that the vertical range is from 350 to $390 \mathrm{~K}$ rather than 340 to $380 \mathrm{~K}$ as in Fig. 8. COBALD data are not available at the time of this observation.

The cirrus clouds appearing moments after the sonde passage at a little lower than $14 \mathrm{~km}$ in lidar data do not exhibit appreciable signal in the sonde humidity profile, although a small maximum of $80 \pm 5 \%$ in $\mathrm{RH}_{\text {ice }}$ is seen at this altitude. Taking these measurements at face value with the assumption that the air masses sampled by the sonde and lidar are identical, a sudden cooling due to a temperature perturbation of at least 2 to $6 \mathrm{~K}$ would be required to explain the cloud development in terms of heterogeneous or homogeneous nucleation, respectively. The depolarization ratio (not shown) indicates all these cirrus layers consist of ice particles. The isentropic back trajectories for 370 to $380 \mathrm{~K}$ levels (not shown) are traced back to the east suggesting possible moistening by deep convection even at the $380 \mathrm{~K}$ level.

\subsection{Statistics of dehydration}

We have seen that the simultaneous observations of water vapour and ice particles by hygrometers and lidar/COBALD sonde, respectively, are very useful in describing the existence or the lack of condensed matter in highly supersaturated regions. We have also shown that the humidity profiles often reflect the difference in the origin of the air masses. In addition to the close look at individual profiles in Sect. 4.1, we will now statistically investigate general features of TTL dehydration as retrieved from our current observation network.

Figure 14 is an extended version of Fig. 7 of Hasebe et al. (2007) providing scatter diagrams of OMR against $\mathrm{SMR}_{\min }$ for six different isentropic levels. For the calculations on the $360 \mathrm{~K}$ surface, the ECMWF temperature has been increased by $2 \mathrm{~K}$ based on the cold bias in the analysis field against the SOWER sonde data we find in Fig. 4. Symbols specify season while colours refer to observation stations. The search for the values of $\mathrm{SMR}_{\min }$ along the backward trajectories has been limited to five days based on the investigation on the validity of the adiabatic assumption by Inai et al. (2013). Special attention is paid to avoid possible impacts of deep convection, which may not only violate the assumed adiabatic 


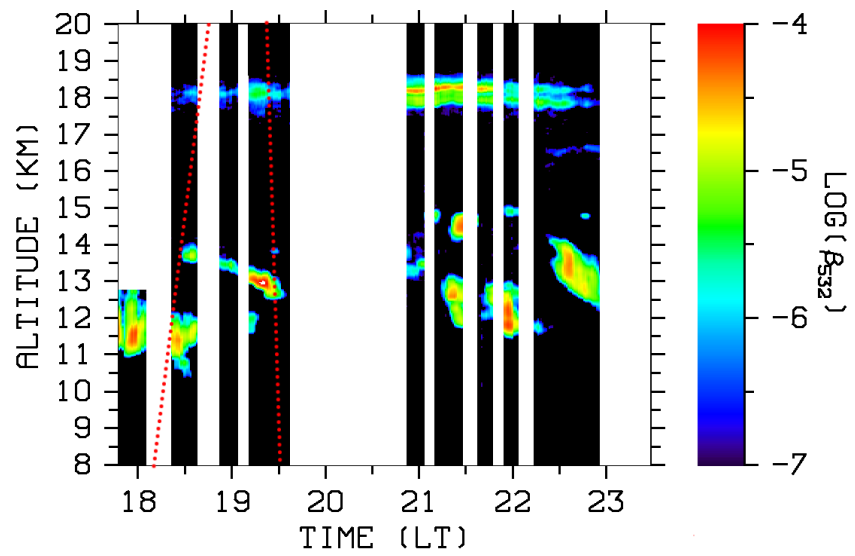

Fig. 13. The same as Fig. 9, but for 14 January 2006. Dotted red lines: ascent and descent of the sounding shown in Fig. 12.

motion in using isentropic trajectories, but also cause the loss of identity of the air parcel. In case where an intrusion of deep convection is suspected, $\mathrm{SMR}_{\min }$ has been sought only from those portions of trajectories after the last of such events. Following Inai et al. (2013), the intrusion is assumed to be subject to the condition $\delta T_{\mathrm{bb}} \leq 12 \mathrm{~K}$. Large error bars in OMR mostly reflect uncertainties of NOAA/FPH and CFH in their early development stages. The basic interpretation of the scatter diagrams is summarised in the following while detailed features for each isentrope are described in Sect. 4.3.

OMR-SMR $_{\min }$ pairs that fall onto the diagonal line (solid line) are likely due to a dehydration event during the upstream 5 days, which depleted the gas phase to the saturation value and subsequently conserved the mixing ratio. However, as nucleation of ice requires a supersaturation $(60-75 \%$ for homogeneous nucleation of ice at temperature characteristic of the western Pacific cold point tropopause; see Koop et al., 2000, for detailed temperature dependence), the OMR might be a factor of 1.6-1.75 higher than $\mathrm{SMR}_{\min }$ without leading to dehydration. The points between the solid and dashed lines, corresponding to saturation and $60 \%$ supersaturation, respectively, might fall into this category. The finite length of time necessary for the air parcel to complete dehydration after initiation of ice formation or incomplete dehydration of layers with too low number densities of ice particles may be other factors that lead to OMR $>S_{M R}$ min. Furthermore, lower levels might experience increases in OMR due to sedimenting ice particles, which fall from higher levels and evaporate at the level of interest. Those points with OMR exceeding $1.6 \times \mathrm{SMR}_{\min }$ beyond the indicated error bars, noticeable at $360 \mathrm{~K}$ and $365 \mathrm{~K}$ surfaces, may well be due to this sedimentation effect.

Pronounced occurrence of $\mathrm{OMR}<\mathrm{SMR}_{\min }$ is found above and below the TTL, i.e., in the stratosphere $(\theta=$ $400 \mathrm{~K})$ and upper troposphere $(\theta=350 \mathrm{~K})$. At $\theta=400 \mathrm{~K}$, which is located above the level of net zero clear-sky radiative heating (LZRH, i.e., where radiative heating and cooling balance each other, located at $125 \mathrm{hPa}$ or about $15.5 \mathrm{~km}$ or $360 \mathrm{~K}$ potential temperature; see Fueglistaler et al., 2009), air has ascended diabatically into warmer regions and the last dehydration event close to the cold point tropopause is longer ago than the 5-day span of the trajectories. As a consequence, except in a few cases, these parcels are much drier than $\mathrm{SMR}_{\min }$. At $\theta=350 \mathrm{~K}$ (around $13 \mathrm{~km}$ ), on the other hand, the diabatic motion outside the convective system is downward, compensating for net radiative cooling. As the tropical convective motions frequently reach $350 \mathrm{~K}$ (Atticks and Robinson, 1983), the air masses sampled by radiosondes are often outflow from convective systems. The water content for such air masses is mostly determined by the temperature of the outflow level (e.g., $-60^{\circ} \mathrm{C}$ ), leading to the near correspondence between OMR and $\mathrm{SMR}_{\min }$ with a factor one order of magnitude larger than that of the upper TTL. The displacement down from the diagonal line will result from the radiatively driven descent that takes place after precipitation and/or evaporation of condensed particles.

\subsection{Statistics of dehydration on the basis of isentropic level}

The scatter diagrams derived from the SOWER chilledmirror hygrometer network data in the Tropical Pacific (Fig. 14) show a wealth of detailed features for the different stations and seasons. Features of the statistics we see in the diagrams are described for each isentrope characterising the dehydration processes taking place in the TTL.

At $350 \mathrm{~K}$ potential temperature, points scatter almost evenly around the diagonal line. Despite relatively large uncertainties, especially those shown in blue (Bandung - BD and Watukosek - WK), these points are suggestive of a bifurcation of backward trajectories (e.g. Hasebe et al., 2007, Fig. 1). As is mentioned in Sect. 4.2, the OMR at this level reflects the coldness of the isentrope in the convective region; large water content in Tarawa (TR; red) will be due to the relatively low altitude of the $350 \mathrm{~K}$ isentropic level combined with active convection in the region. The OMR becomes lower as the station moves westward to Biak (BI; green), Bandung (BD) and Watukosek (WK; blue), and further to Kototabang (KT; purple). Local convection is still high around these stations, but the $350 \mathrm{~K}$ isentrope gradually rises toward the west along the equator, meaning that the SMR at $350 \mathrm{~K}$ tends to be lower toward the Western Pacific. The features found on the $350 \mathrm{~K}$ level along the equator thus reflect the local meteorological condition of the stations. The dryness of Hanoi (HN; light blue) relative to the other stations, on the other hand, requires a different explanation. This station is located in the subtropics where convective activity does not reach such a high altitude. It should also be emphasised that Hanoi is strongly affected by outflow from the tropics, which leads to the seasonal minimum in the upper tropospheric ozone concentration during northern winter (Ogino et al., 2013). 


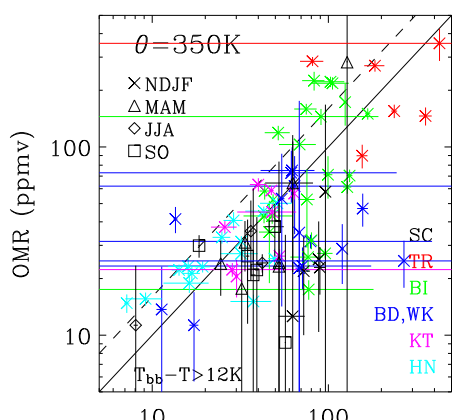

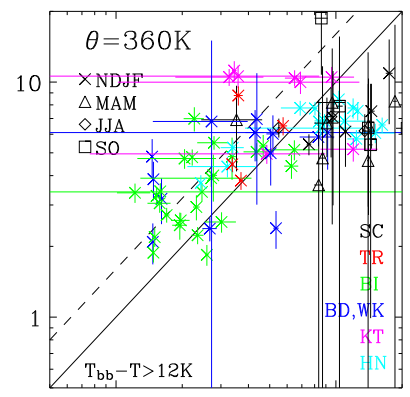

1

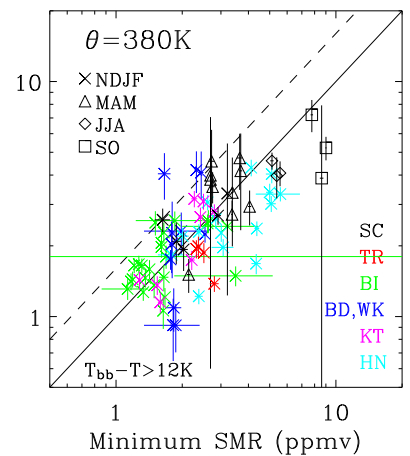

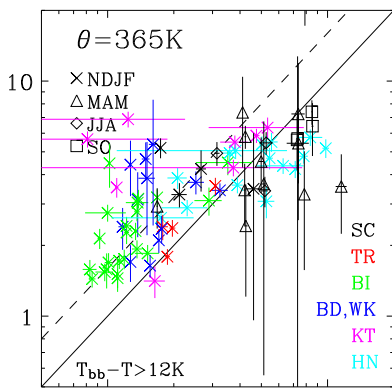

10

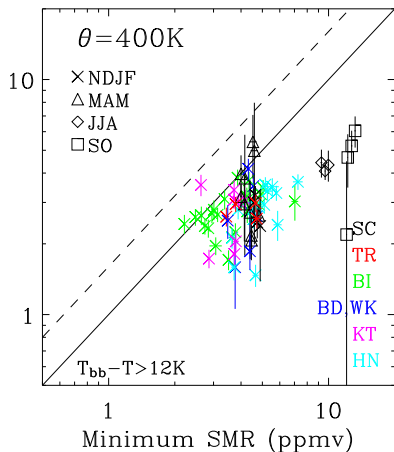

Fig. 14. Scatter diagrams of the minimum saturation mixing ratio $\left(\mathrm{SMR}_{\min }\right)$ experienced within five days before the sounding and the observed water mixing ratio (OMR) on six isentropic levels $(\theta=350-400 \mathrm{~K})$ from seven SOWER stations since 1998. Diagonal line: $\mathrm{OMR}=\mathrm{SMR}_{\min }$, i.e., complete dehydration to the value expected from the minimum along the trajectory. Dashed line: OMR $=$ $1.6 \times \mathrm{SMR}_{\min }$ allowing $60 \%$ supersaturation with respect to ice typically required for homogeneous ice nucleation. In case the advected air parcel is supposed to encounter deep convection $\left(T_{\mathrm{bb}}-T \leq 12 \mathrm{~K}\right), \mathrm{SMR}_{\min }$ is determined from those portions of trajectories after such events. Symbols refer to the seasons, colours to stations: San Cristóbal (SC) located in the Eastern, Tarawa (TR) in the Central, and Biak (BI), Bandung (BD), Watukosek (WK) and Kototabang (KT) in the Western Tropical Pacific, while Hanoi (HN) is in the northern subtropics (Table 1). Vertical bars: estimates of errors in sonde data (Appendix A). Horizontal bars: estimates of $\mathrm{SMR}_{\text {min }}$ deduced from the standard deviation of SMR for segments composed of the air parcel at the time the SMR assumes the minimum. Note different scale for $350 \mathrm{~K}$ (top left panel).

On the $360 \mathrm{~K}$ level, the atmospheric water content measured in OMR and $\mathrm{SMR}_{\min }$ is greatly reduced so that it is less than $10 \mathrm{ppmv}$ and the majority of the points for the northern winter (NW) western tropical observations are found to the upper left side of the diagram. Those points scattered beyond the critical supersaturation (dashed line) suggest that the dehydration is taking place for the air parcel on this isentrope during NW over the Western Tropical Pacific (Sect. 4.2). It is also an indication that the dehydration does not occur immediately, but takes some time before the water is removed to SMR. The driest parcels are found in the Western Pacific (BI, BD, WK) in general, but the OMR appears higher in KT as compared to other stations in the region. The $\mathrm{SMR}_{\min }$ is extremely low for some parcels reaching as low as $1.5 \mathrm{ppmv}$, which is much lower than the average in the lower stratosphere. In contrast, the points for SC (all seasons) and $\mathrm{HN}$ are scattered to the lower right of the diagram with the $S_{M R}$ min similar to, or more than $10 \mathrm{ppmv}$. The values of $\mathrm{SMR}_{\min }$ larger than those of the western tropical stations would be a reflection of relatively high temperature along the air parcel trajectories, while the deviation of the points to the lower right of the diagonal suggests dehydration events more than 5 days before arrival at these stations.

The removal of water from the advected air parcel continues on the $365 \mathrm{~K}$ isentrope. The features remain almost the same as those at $360 \mathrm{~K}$ except that both OMR and $\mathrm{SMR}_{\min }$ are smaller than those at $360 \mathrm{~K}$. Most of the points found below the diagonal line with relatively large uncertainties in OMR are those from the Eastern Pacific in the March-May period in the late 1990s taken using the NOAA/FPH. Some of the points for Hanoi are found to the upper left from the diagonal line, suggesting that cold trap dehydration is also functioning on air parcels advected outward from the tropics on this $365 \mathrm{~K}$ isentrope.

The scatter plots become more compactly distributed near the lower left corner of the diagram as the air parcels rise to reach the $370 \mathrm{~K}$ isentrope. The majority of the points are still found above the diagonal line, but the occasions where OMR $>1.6 \times \mathrm{SMR}_{\min }$ become less frequent, indicating that the dehydration is less effective than that at $360 \mathrm{~K}$ and $365 \mathrm{~K}$. The points for NW are mostly found with the OMR less than 4 ppmv implying that some extreme dehydration, in excess 
of the climatological dryness of the stratosphere, has already taken place.

The points gradually move to the right on the diagram located around the diagonal line as the air parcels ascend to $380 \mathrm{~K}$. On rare occasions parcels are found beyond the critical limit of $1.6 \times \mathrm{SMR}_{\min }$, indicating that the dehydration is almost over before the air parcels reach this isentrope. The mean value of OMR during NW calculated from those in BI, $\mathrm{KT}$ and TR is $1.9 \pm 0.6 \mathrm{ppmv}$ (unbiased standard deviation), while that in NS available only at SC is $4.2 \pm 0.3$ ppmv. These values must reflect the level of dehydration achievable during the horizontal advection. The differences come from two conditions; one from the seasonal march and the other from the east-west contrast. The former constitutes the foundation of the tape recorder signal (Mote et al., 1996) appearing in the seasonal migration of the points for $\mathrm{SC}$ ranging from $\sim 2$ ppmv in NW to $4 \sim 7 \mathrm{ppmv}$ in northern summer (NS) to fall. Unfortunately, the magnitude of the seasonal variation in the Western Tropical Pacific is not available since our observations there are restricted to NW. As a consequence the extreme low values of OMR observed in $\mathrm{BI}$ and $\mathrm{KT}$ are not found in SC.

The movement of points to the right on the diagram continues to $400 \mathrm{~K}$, where almost all points are found to the lower right of the diagonal line. The cold-trap dehydration with horizontal advection no longer functions on the $400 \mathrm{~K}$ isentrope, meaning that the dehydration must have concluded sometime more than five days before the air reaches the $400 \mathrm{~K}$ surface. The NW-mean OMR for BI, KT and TR is $2.8 \pm 0.6$ ppmv. The seasonal amplitude of the OMR is reduced as the extremely low OMRs such as those less than $1.5 \mathrm{ppmv}$ found on $380 \mathrm{~K}$ disappear. This may suggest that some hydration processes such as those associated with the evaporation of once-condensed ice particles and/or irreversible mixing with humid air outside the TTL have occurred before the air reaches $400 \mathrm{~K}$.

\section{Discussion}

Radiosonde observations of water vapour and ozone over the Tropical Pacific conducted during SOWER campaigns are used to analyse the efficiency of cold-trap dehydration taking place in air parcels advected horizontally in the TTL. Chilled-mirror hygrometers such as the FPH and CFH are used to obtain water vapour mixing ratio data suitable for observing the extreme dryness in the tropical upper troposphere, TTL and the lower stratosphere. Estimates of uncertainties in the water vapour mixing ratios are derived, together with an attempt at correcting the phase delay in the frostpoint temperature measurements, to improve our confidence in the degree of supersaturation. The response time given in this procedure has been empirically determined as a function of atmospheric pressure. The stratospheric value of response time adopted in the present study (Table 2) is a little larger than that shown by Vömel et al. (2007b) obtained by comparisons with fast-response fluorescence sensors. The single response time used throughout the analysis period has been determined from CFH observations and may not be appropriate for data obtained from early campaigns as the instrument has been continuously upgraded. The sequence of processing described above, even if incomplete, has improved the present analysis leading to greater confidence in the results.

Trajectory analyses presented in this paper depend on the global analysis field. Although growing numbers of global analyses have emerged with notable differences (e.g. Liu et al., 2010; Schoeberl and Dessler, 2011), our use of the high-resolution model-level ECMWF analysis is based on our recognition that fine vertical resolution in the TTL is important for our study as the temperature perturbations and wind shear associated with large scale atmospheric waves could play a key role in the TTL dehydration. On the other hand, there is a clear limitation as can be seen from the comparison between the analysis field and sonde data as seen in Fig. 4. Fortunately, the wind biases in the TTL are mostly confined to zonal wind between $375 \mathrm{~K}$ and $390 \mathrm{~K}$, while the spatial scale of variabilities becomes larger in this altitude range than in the lower TTL thus the impact of wind bias on the estimates of $\mathrm{SMR}_{\min }$ is more limited. A mean temperature bias of $2 \mathrm{~K}$ on the potential temperature surfaces at $355 \mathrm{~K}$ and $360 \mathrm{~K}$ (but not at $365 \mathrm{~K}$ and above), on the other hand, needs to be considered in the estimation of $\mathrm{SMR}_{\min }$. Our present approach is to assume a $2 \mathrm{~K}$ constant bias in the ECMWF temperature field and add $2 \mathrm{~K}$ to the temperature along the trajectories without considering any change in the trajectories themselves. This is over simplification of the problem, but provides a better estimate of $\mathrm{SMR}_{\min }$ making the judgement of the encounter with deep convection more realistic. As is expected, the points have moved to the righthand side and come closer to the dashed line in Fig. 14 as compared to those without taking this bias into account (not shown). It is interesting to see the uneven shift at potential temperatures $360 \mathrm{~K}$ and $365 \mathrm{~K}$ does not go far beyond the dashed line suggesting that the supersaturation along the trajectories does not greatly exceed the homogeneous nucleation limit. One of the possible ways to get more generalised results is to conduct multi-model comparisons such as being done among climate models within the climate change research community. Systematic comparison among major global analysis fields (Fujiwara et al., 2012), including TTL trajectories, will be an important step still waiting to be done. Another route to attain more confidence in the results will be the use of data assimilation techniques incorporating the observed data in the analysis field. Our preliminary analysis indicates that the improved time resolution in particular in the assimilation field will make the estimates of $\mathrm{SMR}_{\min }$ more realistic.

Supersaturation as large as $179 \pm 14 \%$ of the relative humidity with respect to ice $\left(\mathrm{RH}_{\text {ice }}\right)$ has been observed around 
Table 2. Response time, $\tau$, empirically determined for frostpoint hygrometers and the number of averaging, $2 N+1$, applied to the raw sonde data to derive smoothed frostpoint temperature profiles. $t$ values corresponding to the significance level $\alpha=0.005$ are also shown. See text for the details.

\begin{tabular}{cccccccc}
\hline$p$ & $\tau$ & \multicolumn{2}{c}{$2 N+1$} & \multicolumn{2}{c}{$f(=2 N)$} & \multicolumn{2}{c}{$t(f, \alpha)$} \\
$(\mathrm{hPa})$ & $(\mathrm{s})$ & TMAX & V2C & TMAX & V2C & TMAX & V2C \\
\hline-120 & 10 & 5 & 25 & 4 & 24 & 4.604 & 2.797 \\
$120-150$ & 8 & 3 & 17 & 2 & 16 & 9.925 & 2.921 \\
$150-250$ & 4 & 3 & 9 & 2 & 8 & 9.925 & 3.355 \\
$250-$ & 0 & 3 & 7 & 2 & 6 & 9.925 & 3.707 \\
\hline
\end{tabular}

the cold point tropopause. This value is one of the highest among those observed in cirrus clouds (Krämer et al., 2009). Popp et al. (2007) discussed such high supersaturation with the presence of condensed-phase nitric acid. Unfortunately, the estimates of uncertainty shown above do not correspond to well-defined confidence interval because of the mutual dependence of errors in the profile data (Appendix A1). Therefore, our results may be regarded as close to or within the limit of the homogeneous freezing threshold of Koop et al. (2000). Since such occurrences are rather limited in our observations, more observational evidence is needed to estimate the possible upper limit of supersaturation in the TTL. For this purpose, it is preferable to launch aerosol sensors such as optical particle counters along with the radiosonde (e.g. Iwasaki et al., 2007) since an extremely low concentration of aerosol, below the detection limit of lidars, might be critically important.

The progress of dehydration for the air parcels advected in the TTL is examined by comparing the $\mathrm{SMR}_{\min }-\mathrm{OMR}$ scatter plots among isentropes. Gradual removal of water associated with the air parcels' slow assent in the TTL is reflected in the way the OMR and the corresponding $\mathrm{SMR}_{\min }$ are distributed on the plane (Fig. 14). The near alignment of the points along the diagonal line at $350 \mathrm{~K}$ has been interpreted as an indication of the minor role of horizontal advection on controlling the water content on this isentrope. This is consistent with the idea of Selkirk et al. (2010) that water variability below $350 \mathrm{~K}$ is decoupled from the quasi-horizontal cold trap dehydration, but more related to convective cloud activity. On the other hand, the distribution of the points is not symmetric with respect to the diagonal, but is found to be distributed unevenly to the upper left on the isentropes $360 \mathrm{~K}, 365 \mathrm{~K}$ and $370 \mathrm{~K}$. This is consistent with the findings of Schiller et al. (2009) in which the aircraft observations of water vapour show values larger than $\mathrm{SMR}_{\text {min }}$ below the $380 \mathrm{~K}$ isentrope. They attributed this difference as the recent moistening of the advected air parcels by deep convection. Our interpretation, however, has been to put more emphasis on the progress of the cold-trap dehydration during the horizontal advection accompanied by the gradual ascent in the TTL, because such uneven distributions are not found at $350 \mathrm{~K}$ where the moistening by deep convection is much more frequent than on isentropes above. The diagonal alignment of the $\mathrm{SMR}_{\min }-\mathrm{OMR}$ scatter plots at $380 \mathrm{~K}$ and the increase of OMR from the $380 \mathrm{~K}$ to the $400 \mathrm{~K}$ isentropes is an indication that the dehydration is almost complete at $380 \mathrm{~K}$. However, the detailed process of how this entry value of water is modulated to form stratospheric values is not well understood. Our conclusion on the role of hydration processes (Sect. 4.3) is preliminary and needs to be revisited by studies based on observed data that cover all seasons over the entire tropics.

In the Lagrangian description of the horizontal advection, possible penetration of convective clouds and a subsequent loss of the air parcel's identity is always a matter of concern. In the present analysis, cumulus penetration has been diagnosed by comparing the temperature of the advected air parcel $T$ with the equivalent blackbody temperature $T_{\mathrm{bb}}$ of the underlying atmosphere. Once the condition $\delta T_{\mathrm{bb}} \equiv T_{\mathrm{bb}}-T \leq 12 \mathrm{~K}$ is met, the value $\mathrm{SMR}_{\min }$ has been sought only from those portions of trajectories after such events. Presently there is no conclusive reason for the choice of the critical value $12 \mathrm{~K}$ (see Sect. 3 of Inai et al., 2013). However, the results shown in Fig. 14 do not essentially change with the choice of the critical value. The use of a new method proposed by Hamada and Nishi (2010) could be an alternative, although some of our stations are outside the coverage of the Japanese geostationary satellite, Multifunctional Transport Satellite (MTSAT), necessary for applying their algorithm.

Selkirk et al. (2010) introduced tropopause saturation layer (TSL) whose top was defined by the highest altitude of saturation while the bottom was the altitude of the minimum in the water mixing ratio found below the TSL top. They argued that the water mixing ratio at the cold point tropopause (CPT) often represented that in the stratosphere since the CPT was sometimes created by adiabatic cooling associated with the upward displacement due to atmospheric waves and that the stratospheric entry value of water was effectively determined by the minimum water mixing ratio in the TSL. This argument is based on two observational campaigns conducted in the Eastern Tropical Pacific (Costa Rica) during northern summer, in which the tops of the TSL were $380 \mathrm{~K}$ and $381 \mathrm{~K}$ and the average minima in the TSL water were 5.2 and 4.8 ppmv, respectively. Our observations in the Western Tropical Pacific during northern winter, on the other hand, sometimes encountered supersaturation above $380 \mathrm{~K}$ as was shown in Fig. 12. In this case, the minimum water mixing ratio found in the TSL is $1.27 \mathrm{ppmv}$ on the $379.5 \mathrm{~K}$ and $380.0 \mathrm{~K}$ isentropes in the processed data, while there is little indication of gravity wave disturbances. Such a low value in this particular case must be too low as to be regarded as the stratospheric entry value of water.

The possible role of Kelvin waves on the dehydration of the atmosphere being exchanged between the troposphere and the stratosphere was pointed out first by 
Fujiwara et al. (2001). Eguchi and Shiotani (2004) discussed the importance of the temperature and flow variations associated with the structure of the coupled Kelvin-Rossby waves in the TTL dehydration. Fujiwara et al. (2009) pointed out that the dynamical processes accompanied by the Kelvin waves are important in controlling cirrus formation in the TTL. It is thus quite interesting to see if large scale wave activity might change the progress of dehydration shown in the $\mathrm{SMR}_{\min }-\mathrm{OMR}$ scatter plot (Fig. 14) by sorting the spatiotemporal position of the air parcels in the phase diagram of Kelvin waves. This is left for future studies.

One of the goals of our study to explore the efficiency of cold-trap dehydration is to quantify the amount of water removed during horizontal advection. For this purpose, the Lagrangian approach following the advected air parcels is preferable. That is, by comparing the water amount of a specific air parcel taken by two or more sequential observations, we could explicitly estimate the water budget for the parcel. This water vapour match approach, similar to that applied to ozone depletion in the polar vortex, is being attempted using the SOWER dataset. Since detailed examination of the "match condition" is needed, the results are not presented here, but are described in the companion paper by Inai et al. (2013).

\section{Concluding remarks}

Balloon-borne radiosonde data obtained by chilled-mirror hygrometers and electrochemical concentration cell ozone sondes have been analysed for the study of cold-trap dehydration in the Tropical Tropopause Layer (TTL). A major effort has been made to estimate the uncertainty of the results for the analysis being made on isentropes. Efforts are also made to adjust the inherent phase delay in the frostpoint temperature observed by hygrometers. Statistical uncertainties are determined as well in the Lagrangian description of advected air masses by using a bundle of trajectories initialised in the region surrounding the ground station.

The results are shown for individual soundings and using statistical features characterising the TTL dehydration. Simultaneous observations of gas and liquid/solid phase water by hygrometers and lidar/COBALD sondes, respectively, prove to be useful in describing the efficiency of dehydration in terms of the relative humidity with respect to ice $\left(\mathrm{RH}_{\mathrm{ice}}\right)$. Extremely high values of $\mathrm{RH}_{\mathrm{ice}}$ have been encountered reaching almost $180 \%$ within cirrus clouds in the vicinity of the cold point tropopause. For the confirmation of such findings, further accumulation of observational evidence is still needed. The statistical features of cold trap dehydration are investigated using scatter diagrams between the observed water mixing ratio and the minimum saturation mixing ratio along the back trajectories associated with the observed air mass. The distribution of the points display the manner in which water vapour is removed from air parcels during the course of quasi-horizontal advection accompanied by crossisentropic slow ascent in the TTL. Gross features suggest that the cold-trap dehydration progresses on the isentropes above $360 \mathrm{~K}$ reaching the final stage at around $380 \mathrm{~K}$. Some moistening is also taking place before the air parcel reaches $400 \mathrm{~K}$ where mo more dehydration is expected.

\section{Appendix A}

\section{Detailed procedure applied to sonde data}

\section{A1 Processing on sounding pressure levels}

\section{A1.1 Smoothing of raw sonde data}

The detailed smoothing procedure intended to reduce instrumental noise of the frostpoint hygrometers is described in this subsection. Denote the smoothed profiles of the frostpoint temperature as $\bar{T}_{\mathrm{fr} i}(i=1,2, \cdots)$ :

$\bar{T}_{\mathrm{fr} i}=\frac{1}{2 N+1} \sum_{j=-N}^{N} \hat{T}_{\mathrm{fr}(i+j)}$,

where $\hat{T}_{\mathrm{fr}(i+j)}$ refers to observed frostpoint temperature at the $(i+j)$-th data point. The confidence interval for the true frostpoint temperature, $T_{\mathrm{fr} i}$, is estimated from the variance of the residue, $\hat{T}_{\mathrm{fr} i}-\bar{T}_{\mathrm{fr} i}$, with the aid of the $t$ distribution applicable to samples from unknown population variance:

$\bar{T}_{\mathrm{fr} i}-\Delta T_{\mathrm{fr} i} \leq T_{\mathrm{fr} i} \leq \bar{T}_{\mathrm{fr} i}+\Delta T_{\mathrm{fr} i}, \quad \Delta T_{\mathrm{fr} i} \equiv \frac{s_{i} \times t(f, \alpha)}{\sqrt{2 N+1}}$,

where $t(f, \alpha)$ is the $t$ value corresponding to the degree of freedom $f(=2 N)$ with the confidence level $100(1-2 \alpha) \%$, and $s_{i}$ is the sample standard deviation defined by the rootmean-square differences of the observed values, $\hat{T}_{\text {fri }}$, from smoothed profile, $\bar{T}_{\text {fri }}$ :

$s_{i}=\left\{\frac{1}{2 N} \sum_{j=-N}^{N}\left(\hat{T}_{\mathrm{fr}(i+j)}-\bar{T}_{\mathrm{fr}(i+j)}\right)^{2}\right\}^{\frac{1}{2}}$.

The smoothing interval $2 N+1$ is determined by considering the response time empirically determined as discussed later in Appendix A3. $\alpha$ is taken to be 0.005 in this study leading to a $99 \%$ confidence interval (Table 2). It should be noted, however, that the confidence interval thus derived must not be interpreted as it is, since the set of $2 N+1$ data points taken along the sequential sonde data cannot be regarded as independent samples from a single population; the characteristics of airmass could change during the sonde ascent while independency among data samples is lost by the overlap due to smoothing. Actually those values of $\Delta T_{\text {fri }}$ obtained for the $\mathrm{CFH}$ are often much smaller than those uncertainties deduced by Vömel et al. (2007a). For the purpose of providing a 
practical measure of the observational uncertainties, we have added $0.5^{\circ} \mathrm{C}$ to the values of $\Delta T_{\text {fri }}$ estimated by Eq. (A2) for use throughout this work.

\section{A1.2 Estimates of errors in potential temperature and water mixing ratio}

Denote the definition of potential temperature and the GoffGratch equation as functions $F$ and $G$, respectively. For simplicity, the suffix $i$ is omitted in the following equations:

$\bar{\theta}(\bar{p}) \equiv F(\bar{p}, \bar{T}), \quad \bar{\chi}(\bar{p}) \equiv \frac{\bar{e}_{\mathrm{sat}}}{\bar{p}}=\frac{G\left(\bar{T}_{\mathrm{fr}}\right)}{\bar{p}}$,

on the sounding pressure level $\bar{p}$. By applying the law of propagation of errors, we have the estimates of errors in potential temperature and water mixing ratio as follows:

$$
\begin{aligned}
& \Delta \theta(\bar{p})=\left\{\left(\frac{\partial F}{\partial \bar{p}} \Delta p\right)^{2}+\left(\frac{\partial F}{\partial \bar{T}} \Delta T\right)^{2}\right\}^{\frac{1}{2}}, \\
& \Delta \chi(\bar{p})=\left\{\left(\frac{1}{\bar{p}} \frac{\partial G}{\partial \bar{T}_{\mathrm{fr}}} \Delta T_{\mathrm{fr}}\right)^{2}+\left(\frac{G}{\bar{p}^{2}} \Delta p\right)^{2}\right\}^{\frac{1}{2}} .
\end{aligned}
$$

\section{A2 Projection of sonde data on isentropes}

The water mixing ratio and its estimates of errors on an isentropic level $\theta$ are derived by linear interpolation using values on adjacent sounding pressure levels $\bar{p}_{i}$ and $\bar{p}_{i+1}$ :

$$
\begin{aligned}
& \bar{\chi}(\theta)=\frac{m \times \bar{\chi}_{0}+n \times \bar{\chi}_{1}}{m+n}, \\
& \Delta \chi(\theta)=\left[\sum_{k=0}^{1}\left\{\left(\frac{\partial \bar{\chi}(\theta)}{\partial \bar{\chi}_{k}} \Delta \chi_{k}\right)^{2}+\left(\frac{\partial \bar{\chi}(\theta)}{\partial \bar{\theta}_{k}} \Delta \theta_{k}\right)^{2}\right\}\right]^{\frac{1}{2}} \\
&=\frac{1}{m+n}\left[\left(m \Delta \chi_{0}\right)^{2}+\left(n \Delta \chi_{1}\right)^{2}+\left(\frac{\bar{\chi}_{1}-\bar{\chi}_{0}}{m+n}\right)^{2}\right. \\
&\left.\left\{\left(m \Delta \theta_{0}\right)^{2}+\left(n \Delta \theta_{1}\right)^{2}\right\}\right]^{\frac{1}{2}},
\end{aligned}
$$

where $\bar{\chi}_{k} \equiv \bar{\chi}\left(\bar{p}_{i+k}\right), \quad \Delta \chi_{k} \equiv \Delta \chi\left(\bar{p}_{i+k}\right), \quad \bar{\theta}_{k} \equiv \bar{\theta}\left(\bar{p}_{i+k}\right)$, $\Delta \theta_{k} \equiv \Delta \theta\left(\bar{p}_{i+k}\right), m=\bar{\theta}_{1}-\theta$, and $n=\theta-\bar{\theta}_{0}$. The first two terms in Eq. (A8) arise from the uncertainty in water measurements while the last term is due to the errors in potential temperature on sounding pressure levels. Equations (A7) and (A8) also apply to pressure and temperature to derive $\bar{p}(\theta)$ and $\bar{T}(\theta)$ together with $\Delta p(\theta)$ and $\Delta T(\theta)$ by replacing $\chi$ with $p$ and $T$, respectively. We apply these equations also to other variables such as ozone mixing ratio and geopotential height.

It is worth mentioning here that high resolution radiosondes observe unstable atmospheric layers where the potential temperature does not increase monotonously with respect to altitude. In such cases, sounding pairs with $\bar{\theta}_{i} \leq \theta \leq$ $\bar{\theta}_{i+1}$ cannot be uniquely determined and the interpolation in

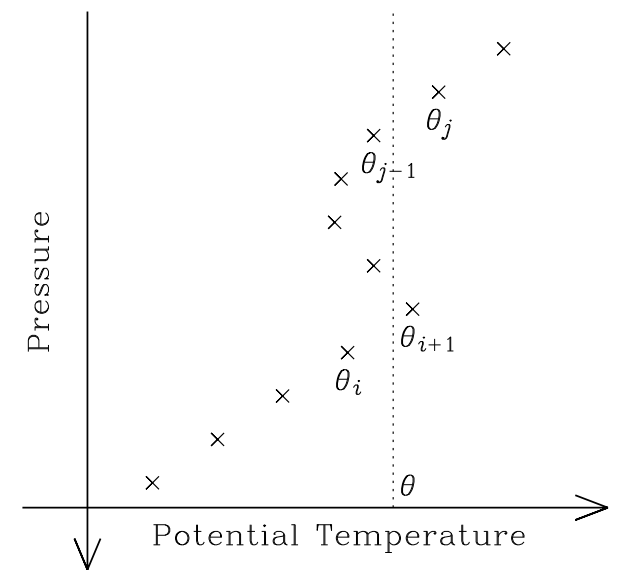

Fig. A1. Schematic illustration of interpolation to an isentropic surface $\theta$ located in an inversion layer encountered by radiosonde observations (crosses). Linear interpolation will be made by using data pairs with $\theta_{i}$ and $\theta_{j}$ in this case.

Eq. (A7) and the estimation of uncertainties in Eq. (A8) could be made by using any sounding pairs with $\bar{\theta}_{i}$ and $\bar{\theta}_{j}$ that satisfy the conditions $\bar{\theta}_{i} \leq \theta \leq \bar{\theta}_{i+1}$ and $\bar{\theta}_{j-1} \leq \theta \leq \bar{\theta}_{j}$. Since such unstable layers are subject to vertical mixing and large scale atmospheric features are better represented by smooth sounding data, we avoid such ambiguity by choosing the pairs $\bar{\theta}_{i}$ and $\bar{\theta}_{j}$ that are found in the lowest altitude for $\bar{\theta}_{i}$ and the highest altitude for $\bar{\theta}_{j}$ that satisfy the above condition (Fig. A1). Usually this choice, at the same time, maximises the estimated uncertainty in Eq. (A8) due to large values of $\left(\bar{\chi}_{1}-\bar{\chi}_{0}\right)^{2}$ multiplied by the uncertainty in potential temperature. We could thus avoid possible underestimation of observational uncertainties associated with the projection of observational data in unstable layers to isentropic coordinates.

\section{A3 Correction of the instrumental phase lag}

The CFH employs a sophisticated digital proportional/integral/derivative (PID) feedback controller to maintain constant frost on a mirror by cooling or heating it (Vömel et al., 2007a). Even with the use of such a system, we cannot get rid of some phase delay in the observed values. For practical purposes the PID parameters are not useful, while the response time is the simplest way to measure the delay. We use values derived by extensive analyses made by Aqua Validation and Instrument Tests (AquaVIT) campaign (Fahey et al., 2009).

Instead of attempting to model the performance here, we make a brief analysis to apply it to our observed data. We assume that the output $q(t)$ results from the convolution of the input $p(t)$ with an $e$-folding time $\tau$ : 


$$
\begin{aligned}
& q(t)=\frac{1}{W} \int_{0}^{t} p(s) e^{-\frac{t-s}{\tau}} \mathrm{d} s, \\
& W=\int_{0}^{t} e^{-\frac{t-s}{\tau}} \mathrm{d} s=\tau\left(1-e^{-\frac{t}{\tau}}\right) .
\end{aligned}
$$

During the continued operation in which $t / \tau \gg 1$,

$q(t)=\frac{1}{\tau} \int_{0}^{t} p(s) e^{-\frac{t-s}{\tau}} \mathrm{d} s$.

Differentiation of Eq. (A11) may lead to the differential form of the input-output relationship

$$
\frac{\mathrm{d} q(t)}{\mathrm{d} t}=\frac{1}{\tau}(p(t)-q(t))
$$

which could be readily rearranged to give the unknown input $p(t)$ from the instrumental output $q(t)$ :

$$
p(t)=q(t)+\tau \frac{\mathrm{d} q(t)}{\mathrm{d} t} .
$$

If the value $\tau$ is known, the input $p(t)$, here the atmospheric frostpoint temperature not affected by the instrumental phase delay, could be estimated from the output $q(t)$, here the observed mirror temperature. This formula is mathematically equivalent to the phase correction applied to the capacitance humidity sensors by Miloshevich et al. (2004).

Though incomplete, the application of Eq. (A13) to the observed profiles successfully reduced the phase difference between the ascending and the descending profiles as shown in Fig. 2. In most cases, the length of smoothing necessary for noise reduction is longer than that for the compensation of the phase delay. The smoothing and phase correction parameters are summarized in Table 2.

Acknowledgements. The authors express hearty gratitude to those colleagues in Instituto Nacional de Meteorología e Hydrología of Ecuador, Lembaga Penerbangan dan Antariksa Nasional of Indonesia, the Meteorological Office of Tarawa, Kiribati, and Aero-Meteorological Observatory of Hanoi, Vietnam for their invaluable contribution in making the campaign observations, and appreciate helpful and constructive comments by two anonymous reviewers. The COBALD sonde was provided by Frank G. Wienhold of Eidgenössische Technische Hochschule (ETH) Zürich, Switzerland. This work was supported by the Japan Society for the Promotion of Science, Grant-in-Aid for Scientific Research (A) 15204043, 18204041, 21244072 and 22241004, and the Global Environment Research Programme (A-1) and (A-071) of the Ministry of the Environment.

Edited by: P. Haynes

\section{References}

Atticks, M. G. and Robinson, G. D.: Some features of the structure of the tropical tropopause, Q. J. Roy. Meteor. Soc., 109, 295-308, 1983.

Brabec, M., Wienhold, F. G., Luo, B. P., Vömel, H., Immler, F., Steiner, P., Hausammann, E., Weers, U., and Peter, T.: Particle backscatter and relative humidity measured across cirrus clouds and comparison with microphysical cirrus modelling, Atmos. Chem. Phys., 12, 9135-9148, doi:10.5194/acp-12-9135-2012, 2012.

Brewer, A. W.: Evidence for a world circulation provided by the measurements of helium and water vapour distribution in the stratosphere, Q. J. Roy. Meteor. Soc., 75, 351-363, 1949.

Danielsen, E. F.: A dehydration mechanism for the stratosphere, Geophys. Res. Lett., 9, 605-608, 1982.

Eguchi, N. and Shiotani, M.: Intraseasonal variations of water vapor and cirrus clouds in the tropical upper troposphere, J. Geophys. Res., 109, D12106, doi:10.1029/2003JD004314, 2004.

Fahey, D. W., Gao, R. S., and Möhler, O.: Summary of the AquaVIT Water Vapor Intercomparison: Static Experiments, personal communications, available at: http://cires.colorado.edu/ $\sim$ voemel/ publications/AquaVITWhitePaper_Final_23Oct2009_22MB.pdf, last access: 6 August 2012, 2009.

Fueglistaler, S. and Haynes, P. H.: Control of interannual and longer-term variability of stratospheric water vapor, J. Geophys. Res., 110, D24108, doi:10.1029/2005JD006019, 2005.

Fueglistaler, S., Wernli, H., and Peter, T.: Tropical troposphereto-stratosphere transport inferred from trajectory calculations, J. Geophys. Res., 109, D03108, doi:10.1029/2003JD004069, 2004.

Fueglistaler, S., Bonazzola, M., Haynes, P. H., and Peter, T.: Stratospheric water vapor predicted from the Lagrangian temperature history of air entering the stratosphere in the tropics, J. Geophys. Res., 110, D08107, doi:10.1029/2004JD005516, 2005.

Fueglistaler, S., Dessler, A. E., Dunkerton, T. J., Folkins, I., Fu, Q., and Mote, P. W.: Tropical Tropopause Layer, Rev. Geophys., 47, RG1004, doi:10.1029/2008RG000267, 2009.

Fujiwara, M., Hasebe, F., Shiotani, M., Nishi, N., Vömel, H., and Oltmans, S. J.: Water vapor control at the tropopause by equatorial Kelvin waves observed over the Galápagos, Geophys. Res. Lett., 28, 3143-3146, 2001.

Fujiwara, M., Shiotani, M., Hasebe, F., Vömel, H., Oltmans, S. J., Ruppert, P. W., Horinouchi, T., and Tsuda, T.: Performance of the Meteolabor "Snow White" chilled-mirror hygrometer in the tropical troposphere: comparisons with the Vaisala RS80 A/HHumicap sensors, J. Atmos. Ocean. Tech., 20, 1534-1542, 2003.

Fujiwara, M., Iwasaki, S., Shimizu, A., Inai, Y., Shiotani, M., Hasebe, F., Matsui, I., Sugimoto, N., Okamoto, H., Nishi, N., Hamada, A., Sakazaki, T., and Yoneyama, K.: Cirrus observations in the Tropical Tropopause Layer over the Western Pacific, J. Geophys. Res., 114, D09304, doi:10.1029/2008JD011040, 2009.

Fujiwara, M., Vömel, H., Hasebe, F., Shiotani, M., Ogino, S.Y., Iwasaki, S., Nishi, N., Shibata, T., Shimizu, K., Nishimoto, E., Canossa, J. M. V., Selkirk, H. B., and Oltmans, S. J.: Seasonal to decadal variations of water vapor in the tropical lower stratosphere observed with balloon-borne cryogenic frostpoint hygrometers, J. Geophys. Res., 115, D18304, doi:10.1029/2010JD014179, 2010. 
Fujiwara, M., Polavarapu, S., and Jackson, D.: A proposal of the SPARC reanalysis/analysis intercomparison project, SPARC Newsletter, 38, 14-17, 2012.

Goff, A. J. and Gratch, S.: Low-pressure properties of water from -160 to $212^{\circ} \mathrm{F}$, Transactions American Society of Heating and Ventilating Engineers, 52, 95-122, 1946.

Hamada, A. and Nishi, N.: Development of a cloud-top height estimation method by geostationary satellite split-window measurements trained with CloudSat Data, J. Appl. Meteorol. Clim., 49, 2035-2049, 2010.

Hasebe, F.: Quasi-biennial oscillations of ozone and diabatic circulation in the equatorial stratosphere, J. Atmos. Sci., 51, 729-745, 1994.

Hasebe, F., Shiotani, M., Vömel, H., Fujiwara, M., Nishi, N., Niwano, M., Uetake, T., Ikeda, M., Ogawa, T., Oltmans, S. J., and Gage, K.: First results from the SOWER/Pacific 1998/1999 campaigns, in: Atmospheric Ozone, Proceedings of the Quadrennial Ozone Symposium, Sapporo, 3-8 July 2000, 783-784, 2000.

Hasebe, F., Fujiwara, M., Nishi, N., Shiotani, M., Vömel, H., Oltmans, S., Takashima, H., Saraspriya, S., Komala, N., and Inai, Y.: In situ observations of dehydrated air parcels advected horizontally in the Tropical Tropopause Layer of the western Pacific, Atmos. Chem. Phys., 7, 803-813, doi:10.5194/acp-7-803-2007, 2007.

Holton, J. R. and Gettelman, A.: Horizontal transport and the dehydration of the stratosphere, Geophys. Res. Lett., 28, 2799-2802, 2001.

Inai, Y., Hasebe, F., Shimizu, K., and Fujiwara, M.: Correction of radiosonde pressure and temperature measurements using simultaneous GPS height data, SOLA, 5, 109-112, doi:10.2151/sola.2009-028, 2009.

Inai, Y., Hasebe, F., Fujiwara, M., Shiotani, M., Nishi, N., Ogino, S.Y., Vömel, H., Iwasaki, S., and Shibata, T.: Dehydration in the tropical tropopause layer estimated from the water vapor match, Atmos. Chem. Phys. Discuss., 13, 633-688, doi:10.5194/acpd13-633-2013, 2013.

Iwasaki, S., Maruyama, K., Hayashi, M., Ogino, S.-Y., Ishimoto, H., Tachibana, Y., Shimizu, A., Matsui, I., Sugimoto, N., Yamashita, K., Saga, K., Iwamoto, K., Kamiakito, Y., Chabangborn, A., Thana, B., Hashizume, M., Koike, T., and Oki, T.: Characteristics of aerosol and cloud particle size distributions in the tropical tropopause layer measured with optical particle counter and lidar, Atmos. Chem. Phys., 7, 3507-3518, doi:10.5194/acp7-3507-2007, 2007.

Jensen, E. and Pfister, L.: Transport and freeze-drying in the tropical tropopause layer, J. Geophys. Res., 109, D02207, doi:10.1029/2003JD004022, 2004.

Jensen, E. J., Toon, O. B., Selkirk, H. B., Spinhirne, J. D., and Schoeberl, M. R.: On the formation and persistence of subvisible cirrus clouds near the Tropical Tropopause, J. Geophys. Res., 101, 21361-21375, 1996.

Koop, T., Luo, B., Tsias, A., and Peter, T.: Water activity as the determinant for homogeneous ice nucleation in aqueous solutions, Nature, 406, 611-614, 2000.

Krämer, M., Schiller, C., Afchine, A., Bauer, R., Gensch, I., Mangold, A., Schlicht, S., Spelten, N., Sitnikov, N., Borrmann, S., de Reus, M., and Spichtinger, P.: Ice supersaturations and cirrus cloud crystal numbers, Atmos. Chem. Phys., 9, 3505-3522, doi:10.5194/acp-9-3505-2009, 2009.
Liu, Y. S., Fueglistaler, S., and Haynes, P. H.: Advectioncondensation paradigm for stratospheric water vapor, J. Geophys. Res., 115, D24307, doi:10.1029/2010JD014352, 2010.

Miloshevich, L. M., Paukkunen, A., Vömel, H., and Oltmans, S. J.: Development and validation of a time-lag correction for vaisala radiosonde humidity measurements, J. Atmos. Ocean. Tech., 21, 1305-1327, 2004.

Mote, P. W., Rosenlof, K. H., McIntyre, M. E., Carr, E. S., Gille, J. C., Holton, J. R., Kinnersley, J. S., Pumphrey, H. C., Russell III, J. M., and Waters, J. W.: An atmospheric tape recorder: the imprint of tropical tropopause temperatures on stratospheric water vapor, J. Geophys. Res., 101, 3989-4006, 1996.

Murphy, D. M. and Koop, T.: Review of the vapour pressures of ice and supercooled water for atmospheric applications, Q. J. Roy. Meteor. Soc., 131, 1539-1565, 2005.

Murray, F. W.: On the computation of saturation vapor pressure, J. Appl. Meteorol., 6, 203-204, 1967.

Newell, R. E. and Gould-Stewart, S.: A stratospheric fountain?, J. Atmos. Sci., 38, 2789-2796, 1981.

Ogino, S.-Y., Fujiwara, M., Shiotani, M., Hasebe, F., Matsumoto, J., Hoang, T. H., and Thanh, N. T. T.: Ozone variations over the northern subtropical region revealed by ozonesonde observations in Hanoi, J. Geophys. Res., accepted, 2013.

Plumb, R. A. and Bell, R. C.: A model of the quasi-biennial oscillation on an equatorial beta-plane, Q. J. Roy. Meteor. Soc., 108, 335-352, 1982.

Popp, P. J., Marcy, T. P., Watts, L. A., Gao, R. S., Fahey, D. W., Weinstock, E. M., Smith, J. B., Herman, R. L., Troy, R. F., Webster, C. R., Christensen, L. E., Baumgardner, D. G., Voigt, C., Kärcher, B., Wilson, J. C., Mahoney, M. J., Jensen, E. J., and Bui, T. P.: Condensed-phase nitric acid in a tropical subvisible cirrus cloud, Geophys. Res. Lett., 34, L24812, doi:10.1029/2007GL031832, 2007.

Richard, E. C., Tuck, A. F., Aikin, K. C., Kelly, K. K., Herman, R. L., Troy, R. F., Hovde, S. J., Rosenlof, K. H., Thompson, T. L., and Ray, E. A.: High-resolution airborne profiles of $\mathrm{CH}_{4}, \mathrm{O}_{3}$, and water vapor near tropical Central America in late January to early February 2004, J. Geophys. Res., 111, D13304, doi:10.1029/2005JD006513, 2006.

Schiller, C., Grooß, J.-U., Konopka, P., Plöger, F., Silva dos Santos, F. H., and Spelten, N.: Hydration and dehydration at the tropical tropopause, Atmos. Chem. Phys., 9, 9647-9660, doi:10.5194/acp-9-9647-2009, 2009.

Schoeberl, M. R. and Dessler, A. E.: Dehydration of the stratosphere, Atmos. Chem. Phys., 11, 8433-8446, doi:10.5194/acp11-8433-2011, 2011.

Selkirk, H. B., Vömel, H., Canossa, J. M. V., Pfister, L., Diaz, J. A., Fernández, W., Amador, J., Stolz, W., and Peng, G. S.: Detailed structure of the tropical upper troposphere and lower stratosphere as revealed by balloon sonde observations of water vapor, ozone, temperature, and winds during the NASA TCSP and TC4 campaigns, J. Geophys. Res., 115, D00J19, doi:10.1029/2009JD013209, 2010.

Shibata, T., Vömel, H., Hamdi, S., Kaloka, S., Hasebe, F., Fujiwara, M., and Shiotani, M.: Tropical cirrus clouds near cold point tropopause under ice supersaturated conditions observed by lidar and balloon-borne cryogenic frost point hygrometer, J. Geophys. Res., 112, D03210, doi:10.1029/2006JD007361, 2007. 
Shibata, T., Hayashi, M., Naganuma, A., Hara, N., Hara, K., Hasebe, F., Shimizu, K., Komala, N., Inai, Y., Vömel, H., Hamdi, S., Iwasaki, S., Fujiwara, M., Shiotani, M., Ogino, S.Y., and Nishi, N.: Cirrus cloud appearance in a volcanic aerosol layer around the tropical cold point tropopause over Biak, Indonesia in January 2011, J. Geophys. Res., 115, D11209, doi:10.1029/2011JD017029, 2012.

Vömel, H., Oltmans, S. J., Hofmann, D. J., Deshler, T., and Rosen, J. M.: The evolution of the dehydration in the Antarctic stratospheric vortex, J. Geophys. Res., 100, 13919-13926, 1995.

Vömel, H., Oltmans, S. J., Johnson, B. J., Hasebe, F., Shiotani, M., Fujiwara, M., Nishi, N., Agama, M., Cornejo, J., Paredes, F., and Enriquez, H.: Balloon-borne observations of water vapor and ozone in the tropical upper troposphere and lower stratosphere, J. Geophys. Res., 107, 4210, doi:10.1029/2001JD000707, 2002.

Vömel, H., Fujiwara, M., Shiotani, M., Hasebe, F., Oltmans, S. J., and Barnes, J. E.: The behaviour of the Snow White chilledmirror hygrometer in extremely dry conditions, J. Atmos. Ocean. Tech., 20, 1560-1567, 2003.
Vömel, H., David, D. E., and Smith, K.: Accuracy of tropospheric and stratospheric water vapor measurements by the cryogenic frost point hygrometer: instrumental details and observations, J. Geophys. Res., 112, D08305, doi:10.1029/2006JD007224, 2007a.

Vömel, H., Yushkov, V., Khaykin, S., Korshunov, L., Kyrö, E., and Kivi, R.: Intercomparisons of stratospheric water vapor sensors: FLASH-B and NOAA/CMDL frost-point hygrometer, J. Atmos. Ocean. Tech., 24, 941-952, 2007b.

Winker, D. M. and Trepte, C. R.: Laminar cirrus observed near the tropical tropopause by LITE, Geophys. Res. Lett., 25, 33513354, 1998. 